\title{
REGIME DOS VENTOS EM CURITIBA E PARANAGUÁ, PARANÁ
}

TERASSI, Paulo Miguel de Bodas - pmbterassi@usp.br Universidade de São Paulo / USP

OLIVEIRA-JÚNIOR, José Francisco de - jose.junior@icat.ufal.br Universidade Federal de Alagoas/UFAL

GALVANI, Emerson - egalvani@usp.br Universidade de São Paulo / USP

\section{CORREIA FILHO, Washington Luiz Félix - wlfcfm@gmail.com} Universidade Federal de Alagoas/UFAL

GOIS, Givanildo de - givanildogois@gmail.com Universidade Federal Fluminense/UFF

SOBRAL, Bruno Serafini - brunossobral@gmail.com Universidade Federal Fluminense/UFF

BIFFI, Vitor Hugo Rosa - vhugorosabiffi@gmail.com Universidade Estadual do Oeste do Paraná/UNIOESTE

\begin{abstract}
RESUMO: Os estudos sobre as características da velocidade e direção dos ventos são relevantes para diversos setores da sociedade, sob aspecto ambiental e econômico. Este trabalho objetiva avaliar o regime dos ventos em multiescala (anual, mensal e horária) nos municípios de Curitiba e Paranaguá (PR). Utilizaram-se os dados horários $(12,18$ e 0 TMG) das estações meteorológicas convencionais pertencentes ao Instituto Nacional de Meteorologia para o período de 1976 a 2010. As rosas de vento e os histogramas foram realizados por meio do programa WRPLOT versão 8.0.0. Para a elaboração dos gráficos boxplot da velocidade e direção dos ventos foram utilizados os softwares $\mathrm{R}$ versão 3.3 .2 e Statistica 7.0. Em Curitiba verificou-se o predomínio de ventos de nordeste $(18,5 \%)$ e leste (15,2\%) associados à atuação da Alta Subtropical do Atlântico Sul (ASAS), enquanto que em Paranaguá a interação entre o relevo adjacente (Serra do Mar) e a circulação da brisa marítima (Oceano Atlântico) condiciona uma maior frequência de ventos de sul (15,3\%). A velocidade média anual dos ventos foi $2,19 \mathrm{~m} . \mathrm{s}^{-1}$ em Curitiba e $2,15 \mathrm{~m} \cdot \mathrm{s}^{-1}$ em Paranaguá. Os meses com as mais elevadas velocidades dos ventos ocorrem entre setembro e março. O ciclo diário apontou o aumento da velocidade dos ventos às 15 horas, atribuída ao aquecimento superficial e à instabilidade atmosférica, sobretudo em Paranaguá (ambiente costeiro), pois esta localidade apresenta uma temperatura média anual $4^{\circ} \mathrm{C}$ mais elevada em relação à Curitiba, que mostrou maiores valores de velocidade dos ventos às 9 e 21 horas em comparação à Paranaguá.
\end{abstract}

PALAVRAS-CHAVES: escoamento atmosférico; fatores fisiográficos; velocidade e direção dos ventos, sistemas meteorológicos.

\section{WIND REGIME IN CURITIBA AND PARANAGUÁ, PARANÁ}

ABSTRACT: Studies about the wind speed and direction characteristics are relevant to several society sectors, both environment and economy. This paper aims to evaluate the winds regime in multiple scales (annual, monthly and hourly) in the Curitiba and Paranaguá municipalities (PR). Were used the time data $(12,18$ and $0 \mathrm{GMT})$ of the conventional meteorological stations belonging to the National Meteorological Institute for the period between 1976 to 2010. Wind roses and histograms were performed using WRPLOT version 8.0.0. Were used the software R version 3.3.2 and Statistica 7.0 to 
elaborate the boxplot graphics of the speed and direction winds were used. In Curitiba was observed the predominance of northeast (18.5\%) and east $(15.2 \%)$ direction winds associated with the performance of the South Atlantic Subtropical High (SASH), while in Paranaguá the interaction between adjacent relief (Serra do Mar) and the circulation of the maritime breeze (Atlantic Ocean) conditions a greater frequency of south winds $(15,3 \%)$. The annual average wind velocity was $2.19 \mathrm{~m} \cdot \mathrm{s}^{-1}$ in Curitiba and $2.15 \mathrm{~m} \cdot \mathrm{s}^{-1}$ in Paranaguá. The months with the highest wind speeds occur between September and March. The daily cycle pointed to the increase of the velocity of the winds at 15 hours, attributed to surface heating and atmospheric instability, especially in Paranaguá (coastal environment), because this locality presents an average annual temperature $4{ }^{\circ} \mathrm{C}$ higher in relation to Curitiba, which showed the highest wind speed values at 9 and 21 hours in comparison to Paranaguá

KEYWORDS: atmospheric flow; physiographic factors; speed and direction wind; meteorological systems.

\section{INTRODUÇÃO}

Os estudos sobre as características da velocidade e direção dos ventos são relevantes para diversos setores da sociedade, principalmente em vários segmentos ambientais e econômicos (COSTA; LYRA, 2012; RANGEL et al., 2018). Segundo Munhoz e Garcia (2008), o conhecimento da direção dos ventos em áreas urbanas possibilita a instalação de indústrias em locais adequados para que a dispersão de poluentes não afetem os setores residenciais, a qualidade do ar de dada região e evitem futuros problemas de saúde (MALEKI et al., 2016).

Segundo Oliveira Júnior et al. (2013) a caracterização do regime de ventos é de suma importância para o monitoramento e avaliação dos poluentes gerados pelo crescimento urbano, residencial e industrial, bem como oriundos de aterros sanitários e do transporte rodoviário. Galvani et al. (1999) ressaltam que as informações sobre os ventos e as suas características são fundamentais em projetos e construções na Arquitetura e na Engenharia Civil, com destaque para a qualidade na ventilação e no conforto térmico humano. A intensidade e direção do vento, a quantidade de material liberado (radionuclídeo), além das condições meteorológicas locais e topografia complexa são importantes na avaliação de segurança de uma Central Nuclear (OLIVEIRA JÚNIOR et al., 2010; SILVA et al., 2017; RANGEL et al., 2018).

Em áreas rurais, a localização dos protetores vegetais (quebra-ventos) utilizados nas atividades agropecuárias se dá pela determinação da direção predominante do vento (ALVES; SILVA, 2011). Segundo Galvani et al. (1999) e Beruski et al. (2009), o conhecimento das características do ventos subsidia a instalação de parques eólicos e para a agricultura, ressalta-se a importância dos ventos como agente no processo de polinização e nos aspectos ligados à economia de água, dada a sua influência na transferência de calor e vapor de água mediante processos advectivos.

Com a preocupação global em relação à preservação do meio ambiente, a energia eólica tem sido destaque como uma matriz energética em diversos países, uma vez que este tipo de energia é limpa e renovável (SILVA et al., 2002, COSTA; LYRA, 2012). Entretanto, nem todas as regiões são aptas a produzi-la, pois a viabilidade da geração de energia elétrica se dá a partir de uma velocidade de $3,0 \mathrm{~m} . \mathrm{s}^{-1}$ (SOUSA, 1993), isso mostra a relevância dos estudos das características dos ventos para a implantação dos parques eólicos e o aproveitamento máximo deste recurso natural. Por exemplo, Silva et al. 
(2004) indicaram que a associação entre a direção predominante e a velocidade dos ventos dão aos estados do Ceará, Rio Grande do Norte, Paraíba, Pernambuco e Sergipe o maior potencial eólico do Nordeste do Brasil (NEB).

Os estudos sobre as características dos ventos podem indicar aspectos da dinâmica atmosférica e a interação entre os demais atributos climáticos (CARDOSO et al., 2012; OLIVEIRA-JÚNIOR et al., 2013). Em um estudo na Serra do Mar no estado do Rio de Janeiro, Sobral et al. (2018) destacaram a influência orográfica na distribuição espacial da velocidade e direção dos ventos e, ainda destacaram os padrões da direção dos ventos com os registros de chuvas. Reboita et al. (2014) caracterizaram a ocorrência da circulação das brisas de vale e montanha em Itajubá (MG) e a associação deste aspectos climáticos com a direção predominante dos ventos, com isso reforçou a importância da rugosidade aerodinâmica $\left(Z_{0}\right)$ provocada pelo relevo no controle das características dos ventos.

Especificamente, o estado do Paraná ainda carece de estudos detalhados acerca das características dos ventos. Oliveira e Borrozzino (2018) indicam que a velocidade dos ventos no Paraná varia de $1,3 \mathrm{~m} . \mathrm{s}^{-1}$ em Morretes a 3,7 m. s em Clevelândia e observaram a redução da velocidade média do vento, tendo sido em média, de 12\% em Londrina, 21\% em Paranavaí, 18\% em Morretes e $9 \%$ em Telêmaco Borba. Estes autores demostram que as rupturas das séries climáticas avaliadas se concentram em sua maioria na década de 1990.

Essencialmente, a área em estudo caracteriza-se pela complexidade e diversidade climática atrelada à maritimidade, a orografia da Serra do Mar e aos diversos mecanismos atmosféricos atuantes. Vanhoni e Mendonça (2008) e Terassi e Galvani (2017) mostraram que o litoral do estado do Paraná, no qual se localiza Paranaguá, caracteriza-se pela abundância de chuvas ( $>2000$ mm anuais) e pelo aumento significativo das chuvas nos meses de verão, o que está associado à atuação da Zona de Convergência do Atlântico Sul (ZCAS) e da massa Tropical atlântica (mTa). Em contraposição, os estudos de Terassi e Galvani (2018) mostraram que Curitiba, situada a sotavento da Serra do Mar, caracteriza-se por uma pluviosidade média anual inferior $(1500 \mathrm{~mm})$ e uma distribuição mensal homogênea singularmente própria ao clima subtropical do Brasil Meridional, no qual a Frente Polar Atlântica (FPA) é o principal mecanismo de geração das chuvas (REBOITA et al., 2010; ZANDONADI et al. 2015).

A área em estudo compreende o município de Curitiba, a capital paranaense e a segunda região metropolitana mais habitada do Sul do Brasil, a região metropolitana de Curitiba (RMC), com uma população de 3.537.894 habitantes, sendo que o também é o mais populoso do Sul, com 1.917.185 habitantes, segundo as estimativas do Instituto Brasileiro de Geografia e Estatística (IBGE,2018). Por sua vez, Paranaguá destaca-se por ser a mais populosa do litoral paranaense (153.666 habitantes) e tem na atividade portuária sua principal renda econômica, sendo o Porto de Paranaguá um dos maiores portos graneleiros da América Latina (APPA, 2018).

Com uma das maiores taxas de crescimento urbano do Brasil desde a década de 1970, Danni-Oliveira (2000) ressalta a urgência no monitoramento dos poluentes do ar em Curitiba, sendo que as características dos ventos é um dos aspectos mais relevantes no suporte à qualidade ambiental urbana, dado o seu papel desempenhado pelos ventos na dispersão de poluentes e qualidade do ar. Considerando a relevância da investigação sobre as características dos 
ventos, este trabalho objetiva avaliar as características de velocidade e direção dos ventos em multiescala (anual, mensal e horária) no período de 35 anos para os municípios de Curitiba e Paranaguá, Paraná.

\section{MATERIAIS E MÉTODOS}

\subsection{LOCALIZAÇÃO E CARACTERIZAÇÃO CLIMÁTICA DA ÁREA EM ESTUDO}

Os municípios de Curitiba e Paranaguá localizam-se no leste paranaense (Figura 1). Paranaguá situa-se na Planície Litorânea e caracteriza-se por uma pluviosidade média anual de $2.187,5 \mathrm{~mm}$ e pela temperatura média anual de $21,4^{\circ} \mathrm{C}$, o que designa o tipo climático "Cfa", subtropical quente úmido, de acordo com Vanhoni e Mendonça (2008). As maiores médias de temperatura do ar ocorrem entre janeiro e março, superior a $25^{\circ} \mathrm{C}$, mesmo período em que ocorrem os maiores totais de chuvas mensais ( $>260 \mathrm{~mm}$ ). Nos meses de junho, julho e agosto, Paranaguá registra as menores temperaturas médias $\left(<18^{\circ} \mathrm{C}\right)$ e os menores totais de pluviosidade em agosto (75 mm) (MELLO et al., 2017) (Figura 2).

Segundo o Instituto Nacional de Meteorologia - INMET (INMET, 2018), Curitiba apresentam uma pluviosidade média anual de $1.507,4 \mathrm{~mm}$ e uma temperatura média anual de $17,4^{\circ} \mathrm{C}$, caracterizando-as pelo tipo climático "Cfb", subtropical brando úmido (ÁLVARES et al., 2013). Os dados do INMET (2018) mostram que Curitiba caracteriza-se pela homogeneidade da distribuição da pluviosidade mensal, com os maiores valores entre dezembro e fevereiro $(>150$ $\mathrm{mm}$ ) e uma pluviosidade média inferior a $80 \mathrm{~mm}$ apenas no mês de agosto (77 $\mathrm{mm}$ ). Desta forma, a capital mais fria do país registra médias próximas a $14^{\circ} \mathrm{C}$ em junho e julho, enquanto que nos meses de janeiro e fevereiro as médias são de aproximadamente $21^{\circ} \mathrm{C}$ (Figura 2).

A seleção destas estações meteorológicas se deu pelas singularidades do ponto de vista climático descrito anteriormente. Enquanto que na Planície Litorânea os totais pluviais e as médias térmicas são maiores devido à influência das baixas altitudes e à maritimidade, marcadamente com uma elevação dos totais de pluviosidade nos meses de verão, no Primeiro Planalto paranaense (MAACK, 2012), representado pela localidade de Curitiba, as médias térmicas e os totais de pluviosidade são inferiores em comparação ao Litoral por situaremse no reverso da Serra do Mar e em maiores elevações. Além disso, em Curitiba há uma maior influência dos mecanismos atmosféricos do domínio subtropical, como a FPA e a massa Polar atlântica (mPa), tendo em vista suas características de distribuição mensal da pluviosidade e temperaturas médias do ar. 


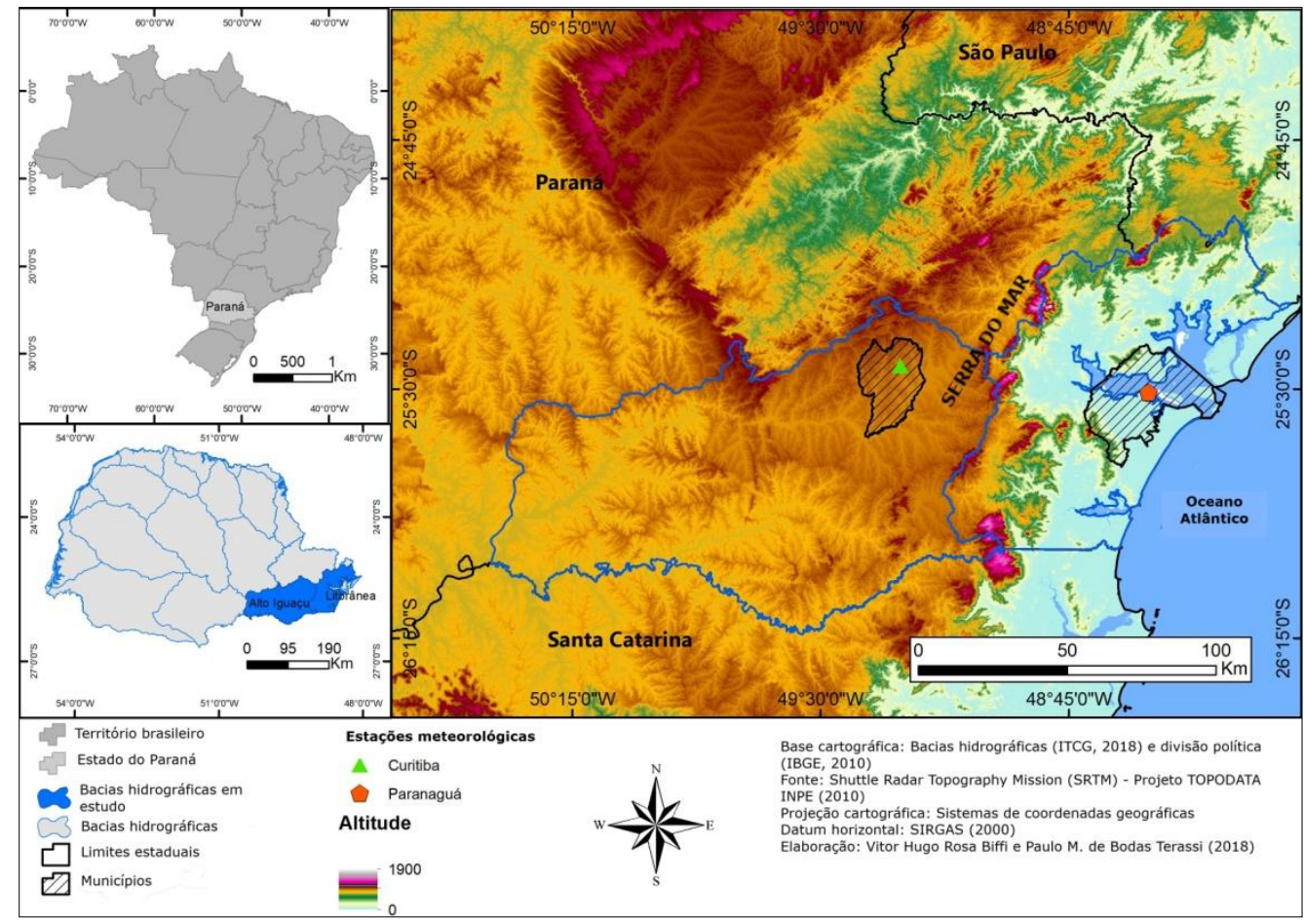

Figura 1 - Localização da área de estudo com as estações meteorológicas de Curitiba e Paranaguá, respectivamente.

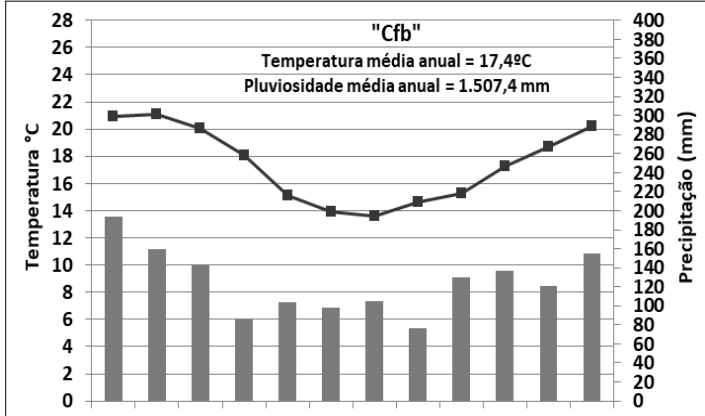

(A)
Jan Fev Mar Abr Mai Jun Jul Ago Set Out Nov Dez Precipitação (mm) -Temperatura ${ }^{\circ} \mathrm{C}$

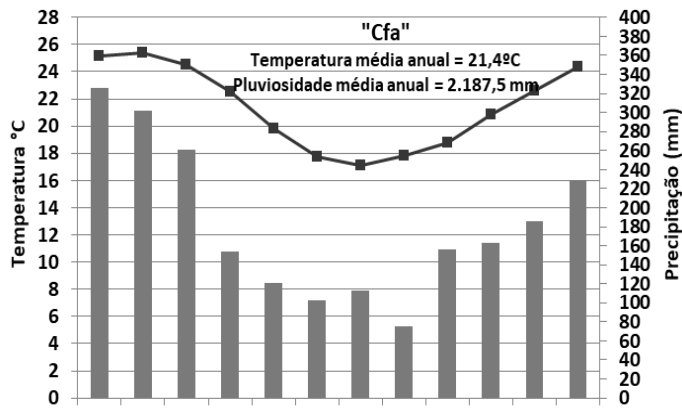

Jan Fev Mar Abr Mai Jun Jul Ago Set Out Nov Dez Mês

(B) Precipitação $(\mathrm{mm}) \rightarrow$-Temperatura ${ }^{\circ} \mathrm{C}$

Figura 2 - Climograma e a classificação climática para Curitiba (A) e Paranaguá (B), leste do Paraná, Brasil. Fonte: Terassi e Galvani (2018).

\subsection{PROCEDIMENTOS METODOLÓGICOS}

Foram utilizados os dados horários das 09, 15 e 21 horas $(12,18$ e 00 TMG) registrados em anemômetros instalados a $10 \mathrm{~m}$ de altura nas estações meteorológicas convencionais (EMC), pertencentes ao INMET, para o período de 1976 a 2010 (INMET, 2019). As EMC de Curitiba e Paranaguá representam suas regiões fisiográficas por situarem-se, respectivamente, a uma altitude de 923 e 4,5 metros, e apresentaram 1,9\% (728) e 10,5\% (4026) de registros ausentes (Tabela 1). 
Tabela 1 - Informações gerais dos dados das EMC de Curitiba e Paranaguá.

\begin{tabular}{c|c|c|c|c|c|c}
\hline $\begin{array}{c}\text { Código } \\
\text { OMM }\end{array}$ & $\begin{array}{c}\text { Estação } \\
\text { Meteorológica }\end{array}$ & $\begin{array}{c}\text { Lat. } \\
(\mathbf{0} \mathbf{S})\end{array}$ & $\begin{array}{c}\text { Lon. } \\
(\mathbf{0} \mathbf{W})\end{array}$ & $\begin{array}{c}\text { Alt. } \\
(\mathbf{m})\end{array}$ & $\begin{array}{c}\text { Falhas } \\
(\mathbf{\%})\end{array}$ & $\begin{array}{c}\text { Registros } \\
\text { utilizados }\end{array}$ \\
\hline 83842 & Curitiba & 25,43 & 49,26 & 923,0 & 1,9 & 37621 \\
\hline 83844 & Paranaguá & 25,23 & 48,51 & 4,5 & 10,5 & 34323 \\
\hline
\end{tabular}

As informações das direções $\left(^{\circ}\right)$ e velocidades dos ventos $\left(m . \mathrm{s}^{-1}\right)$ foram usadas para a elaboração das rosas de vento e histogramas por meio do programa WRPLOT versão 8.0.0 (LAKES, 2017). A partir da rosa dos ventos é possível relacionar a intensidade e direção dos ventos com sua frequência. Os círculos concêntricos indicam a porcentagem de ocorrência de cada direção do vento e as cores indicam a intensidade do vento.

Para a elaboração dos gráficos boxplot (máximo, mínimo, 10 quartil, 30 quartil, mediana, amplitude interquartílica e os valores discrepantes - outliers) da velocidade e direção dos ventos (análise exploratória) foi utilizado o software ambiente $R$ versão 3.3.2 (R CORE TEAM, 2016). As análises estatísticas para a escala horária foram feitas no software Statistica $10 \mathrm{com}$ a representação em gráficos de Boxplot. Consideraram-se como outliers os registros horários entre 99,1 e $99,9 \%$ e os extremos de ventos referem-se aos totais superiores a $99,9 \%$ dos quantis.

\section{RESULTADOS E DISCUSSÕES}

\subsection{ESCALA ANUAL}

Os dados registrados em Curitiba e Paranaguá indicaram calmaria para $30,6 \%$ e $32,6 \%$ das observações durante o período de estudo, nesta ordem, para a escala anual. A classe dos ventos entre 1 a $2 \mathrm{~m} . \mathrm{s}^{-1}$ foi predominante em Curitiba $(54,5 \%)$ e Paranaguá $(47,4 \%)$ e os registros superiores a $2 \mathrm{~m}$. s $\mathrm{s}^{-1}$ se deram em $14,9 \%$ e $16,3 \%$ dos registros (Figura $3 a$ e $3 c$ ). Estas calmarias aproximam-se aos 26,9\% observados por Galvani et al. (1999) para Maringá (PR) e são inferiores aos 38,7\% obtidos por Barbano et al. (2003) em Campinas (SP). Entretanto, estes valores de calmaria obtidos nas localidades do presente trabalho são superiores ao demonstrado para a Região Metropolitana do Rio de Janeiro por Pimentel et al. (2014), que estiveram entre 3,4 e 24,9\%.

Considera-se que a velocidade dos ventos nestas localidades é baixa em comparação às localidades do estado de Alagoas investigadas por Costa e Lyra (2012), que obtiveram velocidades médias anuais entre 5,3 e 7,1 m. s${ }^{-1}$, sendo que os histogramas indicaram a predominância das classes de ventos entre 6 a $8 \mathrm{~m} . \mathrm{s}^{-1}$ para as regiões do Agreste e Sertão, considerado como excelente para a geração de energia eólica. Outro exemplo, Araújo et al. (2019) observaram que em Petrolina (PE) a velocidade média anual dos ventos é de 3,02 m. s${ }^{-1}$, cerca de 3 vezes mais que o obtido para o leste paranaense neste estudo. Por sua vez, Carneiro e Carvalho et al. (2010) mostraram que algumas localidades do Piauí e Pernambuco tem médias mensais entre 8 e $11 \mathrm{~m}$. s${ }^{-1}$. Esta condição de altas velocidades dos ventos no NE brasileiro está relacionada às altas taxas de insolação o ano todo e, consequentemente, às elevadas temperaturas do ar que junto às condições de relevo condicionam a ventos de maiores velocidades. 
Em Petrópolis, situada na região serrana do estado do Rio de Janeiro, Sobral et al. (2018) mostraram $61,6 \%$ dos registros de ventos estiveram entre 2 e $4 \mathrm{~m} . \mathrm{s}^{-1}$, enquanto que em Curitiba e Paranaguá estas classes representam apenas $14,6 \%$ e $16,1 \%$ dos registros totais anuais, nesta ordem. Veneziani et al. (2013) observaram para o Núcleo Cunha, no Parque Estadual Serra do Mar (SP) uma velocidade média anual dos ventos de $2 \mathrm{~m} . \mathrm{s}^{-1}$, embora tenha ocorrido calmaria em cerca de $58 \%$ do período analisado.

Quanto à direção anual dos ventos, observa-se a predominância dos ventos nas direções NE (18,5\%) e E (15,2\%) em Curitiba, ao passo que Paranaguá caracteriza-se pelas direções $S$ e E, ambas as direções com 15,2\% na frequência anual (Figura $3 b$ e $3 d$ ). Em Curitiba, as direções de NE a $E$ são prevalecentes devido à atuação da Alta Subtropical do Atlântico Sul (ASAS) e se assemelham ao observado por Galvani et al. (1999) para Maringá (PR), Leite e Virgens Filho (2006) para Ponta Grossa (PR), Beruski et al. (2009) para Lapa (PR), Silva et al. (2016) para Dourados (MS) e Araújo et al. (2019) para Petrolina (PE). O estudo realizado por Sobral et al. (2018) para a região da Serra do Mar no estado do Rio de Janeiro mostraram que as direções dos ventos predominantes entre NE a E estão diretamente associadas aos baixos totais pluviométricos e, portanto, as condições de atuação da ASAS (REBOITA et al., 2010, ZERI et al., 2011).

Em Campinas, embora ocorra outras direções predominantes dos ventos ao longo do ano, o estudo de Barbano et al. (2003) indicaram que os ventos de SE prevalecem e correspondem a $34 \%$ da série temporal. Segundo Wahrlich et al. (2018), o estado de Santa Catarina caracteriza-se pelas direções predominantes de $\mathrm{N}$ e $\mathrm{NE}$, relacionado à atuação da ASAS e, contudo, em algumas localidades a orografia e a circulação de brisa vale-montanha favorece os ventos de sudoeste (SW). Silva et al. (2002) mostraram que a regiões do NEB apresenta a direção predominante dos ventos de $L$, com variações entre NE e SE.

Em Paranaguá, a direção predominante dos ventos de $S(15,3 \%)$ se dá pela interação entre o relevo da Serra do Mar e a circulação da brisa marítima, em uma condição similar ao identificado nas localidades de Navegantes (SC) por Truccolo (2011) e em alguns setores da RMRJ por Pimentel et al. (2014) e Oliveira-Júnior et al. (2017). Segundo Mello et al. (2017), em Paranaguá há uma persistência maior dos ventos oriundos de $S$ para $23,6 \%$, para o período de 1961 a 2016, com base nos dados disponibilizados pelo INMET similar ao do estudo, o que corroboram com os resultados obtidos. A direção predominante de ventos oriundos de $S$ diferencia-se pelo padrão predominante das demais localidades da região Sul e Sudeste brasileiro (NE-SE), evidenciando que a circulação de brisa marítima se sobrepõe à atuação da ASAS.

As velocidades médias anuais dos ventos foram de 2,19 e 2,15 m. s. em Paranaguá e Curitiba, respectivamente. Os valores da estatística descritiva para a velocidade dos ventos foram similares em ambas estações, exceção dada pela mediana, que mostrou $2 \mathrm{~m} \cdot \mathrm{s}^{-1}$ para Curitiba e $1,6 \mathrm{~m} \cdot \mathrm{s}^{-1}$ para Paranaguá, além do máximo absoluto anual, em 12,5 e 10,5 m. s${ }^{-1}$, na mesma ordem anterior. Para a direção dos ventos, observou-se o domínio dos ventos da direção $\mathrm{S}$ em Paranaguá, com $182,1^{\circ}$ e $180^{\circ}$ para a média e a mediana. Por sua vez, Curitiba mostrou uma média diferente da frequência observada pela figura $3 b$, sendo tal parâmetro em $165,9^{\circ}$ (SSE), que se dá justamente pela maior frequência dos 
ventos de NW e W em relação a Paranaguá, ao passo que a mediana mostra de forma mais adequada o sentido dos ventos predominantemente oriundos de $\mathrm{E}$ $\left(90^{\circ}\right)$. O desvio padrão mostrou que tanto a velocidade quanto a direção dos ventos apresentam uma maior variação em Curitiba em relação à Paranaguá (Tabela 2).

(a)

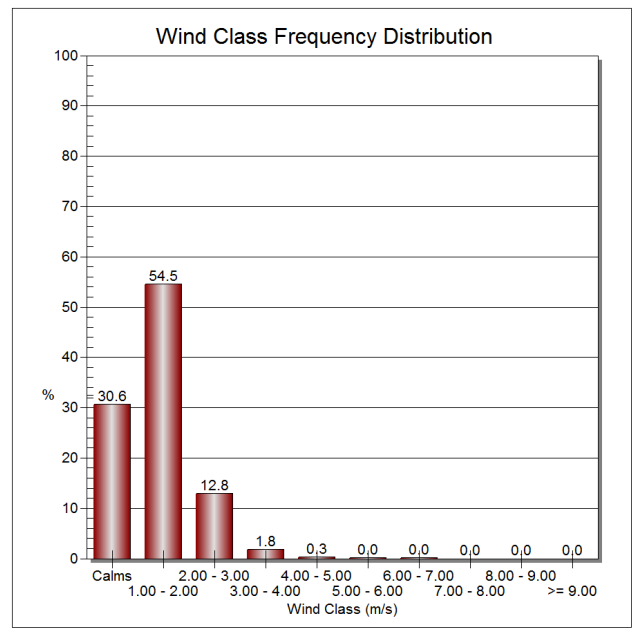

(c)

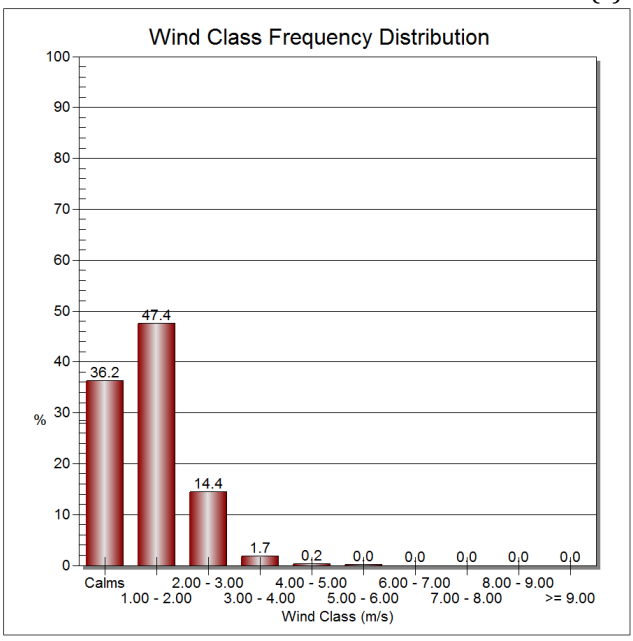

(b)

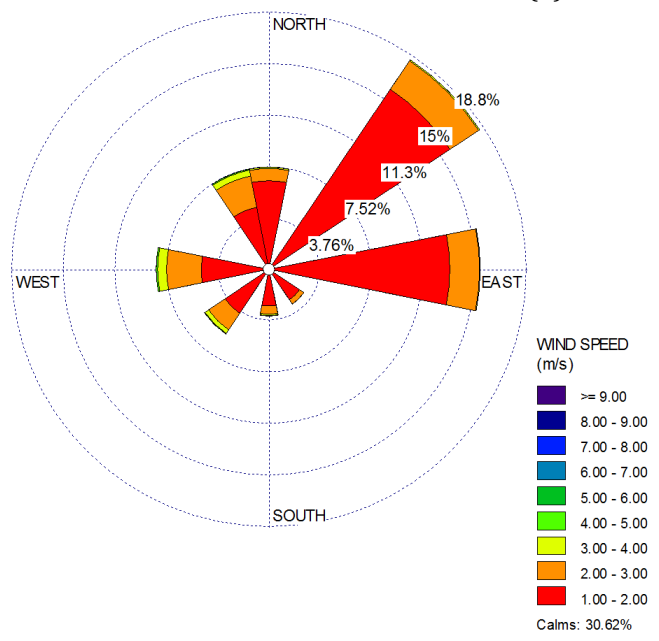

(d)

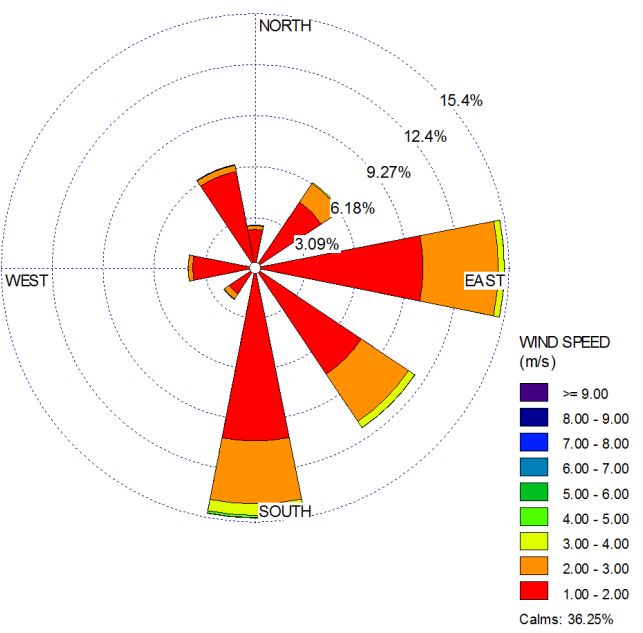

Figura 3 - Histograma da velocidade dos ventos $\left(\mathrm{m} . \mathrm{s}^{-1}\right.$ ) em Curitiba (a) e Paranaguá (c) e rosa dos ventos (\%) para Curitiba (b) e Paranaguá (d) na escala anual. 
Tabela 2 - Estatística descritiva da velocidade $\left(\mathrm{m} . \mathrm{s}^{-1}\right)$ e direção $\left(^{0}\right)$ dos ventos em Curitiba e Paranaguá, Paraná.

\begin{tabular}{c|c|c|c|c}
\hline \multirow{2}{*}{$\begin{array}{c}\text { Parâmetros } \\
\text { estatísticos }\end{array}$} & \multicolumn{2}{|c|}{ Curitiba } & \multicolumn{2}{c}{ Paranaguá } \\
\cline { 2 - 5 } & Velocidade & Direção & Velocidade & Direção \\
\hline Mínimo & 0,00 & 0,00 & 0,00 & 45,00 \\
\hline 10 Quartil & 1,10 & 45,00 & 1,10 & 90,00 \\
\hline Média & 2,19 & 165,90 & 2,15 & 182,10 \\
\hline Mediana & 2,00 & 90,00 & 1,60 & 180,00 \\
\hline 30 Quartil & 3,00 & 270,00 & 3,00 & 270,00 \\
\hline Max & 12,50 & 360,00 & 10,50 & 360,00 \\
\hline Desvio Padrão & 1,33 & 119,38 & 1,30 & 94,64 \\
\hline
\end{tabular}

Observa-se que não há uma excepcional variabilidade da velocidade dos ventos nas localidades em estudo para a escala anual. Ao longo dos 35 anos, notou-se em Curitiba os valores da mediana foram superiores a 2,5 m. s${ }^{-1}$ nos primeiros anos da série histórica, em 1977 e entre 1980 e 1983, tendo uma diminuição significativa da velocidade até os anos de 1991, 1992 e 1993, os quais registraram medianas inferiores a $1,8 \mathrm{~m} . \mathrm{s}^{-1}$ (Figura $4 \mathrm{a}$ ). Para a variável direção dos ventos, há uma concentração dos valores entre os quadrantes de $135^{\circ}$ a 1800. Às exceções estão nos anos de 1979, 1981, 1999, 2001 e 2009, com valores ligeiramente superiores a $180^{\circ}$. Isto mostra o quão importante são os ventos de direção W e NE para a composição da série histórica, embora a predominância dos ventos em Curitiba seja de NE e E (Figura 5a).

Em Paranaguá, os valores mais destoantes da mediana da velocidade dos ventos ocorreram em 1984, inferior a 1,5 m. s${ }^{-1}$, enquanto que em 1976 os valores anuais superaram os $2,8 \mathrm{~m}$. s${ }^{-1}$. Verificou-se o domínio de anos em que a mediana da velocidade dos ventos esteve entre 2,0 e 2,5 m. s${ }^{-1}$, atestando a baixa variabilidade anual deste atributo climático (Figura 4b). Destaca-se que a direção dos ventos em Paranaguá esteve predominantemente de $135^{\circ}$ a $180^{\circ}$, com uma concentração menor de registros inferiores a $135^{\circ}$ em relação a Curitiba. Os valores superiores a $180^{\circ}$ e que foram determinantes para que a síntese da série temporal mostrasse limiares superiores ao mencionado acima e, consequentemente a predominância dos ventos de S, ocorreu entre 1977 e 1984, 1986 e 1989, 2007 e 2010 e em 1992 (Figura 5b).
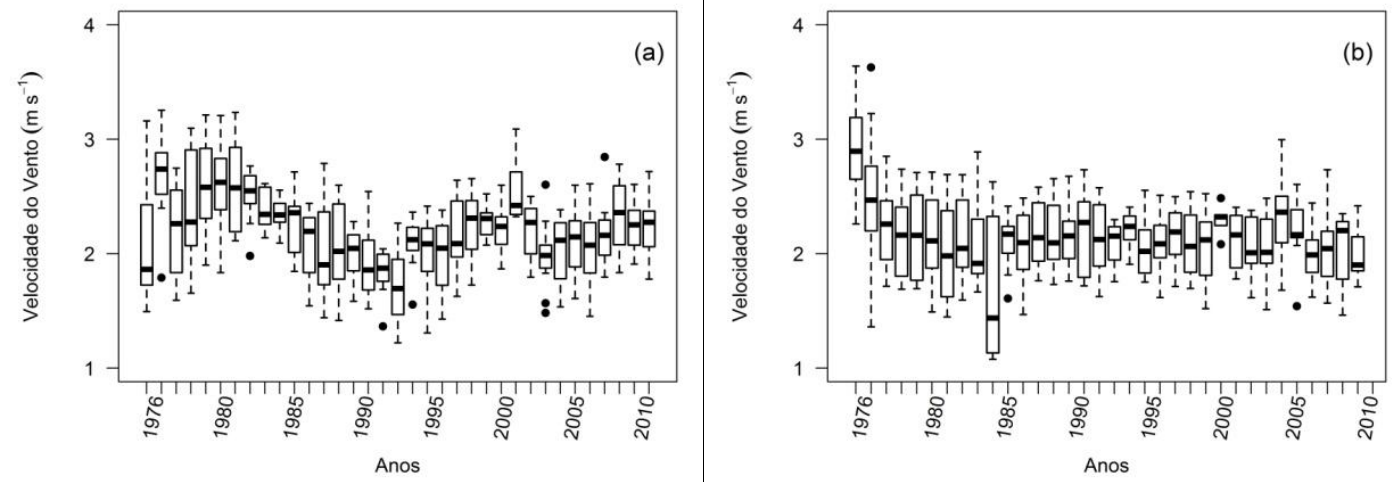

Figura 4 - Boxplot da velocidade anual dos ventos (m. $\mathrm{s}^{-1}$ ) em Curitiba (a) e Paranaguá (b) entre 1976 e 2010. 

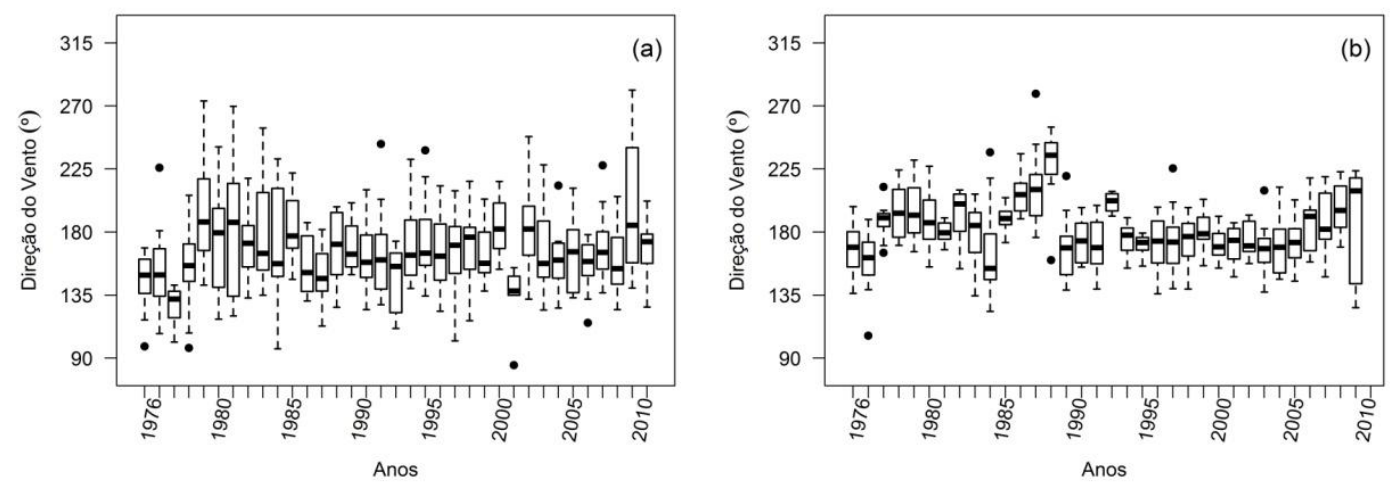

Figura 5 - Boxplot da direção ( ${ }^{\circ}$ ) anual dos ventos em Curitiba (a) e Paranaguá (b) entre 1976 e 2010.

\subsection{ESCALA MENSAL}

Identificou-se que em Curitiba a frequência foi superior a $35 \%$ do regime de calmaria, que por sua vez ocorreu entre abril e agosto, com maior registro em maio $(42,8 \%)$, ao passo que este limiar de ventos calmos se supera a $35 \%$ entre março a setembro em Paranaguá, tendo nesta localidade o maior valor em junho $(45,2 \%)$. Em novembro observa-se a menor frequência de calmaria tanto para Curitiba $(17,7 \%)$ quanto para Paranaguá $(28,0 \%)$, inclusive sendo este 0 mês dos ventos de maiores intensidades, em 2,71 m. s${ }^{-1}$ e $2,56 \mathrm{~m} . \mathrm{s}^{-1}$, nesta ordem (Figuras 6, 7, 8 e 9).

Os resultados descritos anteriormente se assemelham aos obtidos por Silva et al. (2012) e Oliveira-Júnior (2013) para o município de Seropédica (RJ), Baixada Fluminense, localidade na qual observaram que as maiores velocidades dos ventos ocorrem de outubro a dezembro. Mello et al. (2017) mostraram que em Paranaguá os ventos mais intensos ocorrem entre setembro e março, tendo o valor máximo em novembro $\left(2,3 \mathrm{~m} . \mathrm{s}^{-1}\right)$ e o menores valores em junho e julho $\left(1,4 \mathrm{~m} . \mathrm{s}^{-1}\right)$, valores inferiores ao observado para a série temporal em estudo.

Os ventos de direção NE e E predominam em Curitiba de setembro a abril, com frequências superiores a $17 \%$ neste período para os ventos de NE. No entanto, entre maio e agosto verifica-se em Curitiba o aumento dos ventos oriundos de NW, W e SW, tendo no mês de junho o único em que a direção predominante é de W (12,5\%)-(Figuras 6 e 7). Este resultado se difere ao identificado por Castelhano e Roseghini (2018) para Curitiba, pois estes autores observaram que a capital paranaense apresenta ventos oriundos de NE a SE em todos os meses do ano sem exceções, embora o estudo destes autores abranja outra série temporal (2004-2016) e registrada em uma estação meteorológica pertencente ao Sistema Meteorológico do Paraná (SIMEPAR).

Em Tangará da Serra, localizada no sudoeste do Mato Grosso, Dallacorte et al. (2010) observaram que há o domínio de ventos de NE, com exceção dos meses de agosto e setembro (S). Estes autores mostraram que os quadrantes de SW a NW são aqueles em que ocorrem as menores frequências relativas mensais dos registros. 
Em Paranaguá, observa-se que o vento de direção $S$ é o mais frequente de março a outubro e, entretanto, entre novembro e fevereiro verifica-se o predomínio dos ventos de $\mathrm{E}(>18 \%)$. Para uma série temporal de dados diferente a utilizada neste trabalho (1961-2016), Mello et al. (2017) indicaram que o vento $S$ é predominante na maioria dos meses do ano, com exceção de dezembro e fevereiro (E) e de outubro (SE). O aumento da direção dos ventos de quadrante de NE a SE durante os meses mais quentes (setembro a abril) é atribuída aos movimentos sazonais dos centros de alta pressão do Atlântico e a atuação mais frequente da mTa, conforme apontam Vanhoni e Mendonça (2008) e Zandonadi et al. (2015).

Nota-se um aumento significativo dos ventos de NW em Paranaguá de março a julho, tendo a maior frequência relativa observada no mês de junho $(9,5 \%)$, sendo este aumento de ventos do quadrante NW um padrão similar ao observado em Curitiba. Estes resultados se assemelham aos obtidos por Zeri et al. (2011), Oliveira Júnior et al. (2013) e Sobral et al. (2018) em localidades do estado do Rio de Janeiro, que indicaram a maior frequência de ventos entre os quadrantes NW a SW durante o inverno devido à maior atuação da frente polar atlântica.

Reboita e Kruche (2018) identificaram para Rio Grande (RS) o aumento da velocidade dos ventos para os meses de outubro e novembro, com valores médios superiores a $4 \mathrm{~m}$. $\mathrm{s}^{-1}$, e os meses de maio e junho mostraram as médias mensais inferiores a $3 \mathrm{~m} . \mathrm{s}^{-1}$, um padrão similar ao observado neste estudo. As autoras sugerem que o aumento e predominância dos ventos de SW no período de abril a julho naquela região sul-rio-grandense está associada ao predomínio da passagem da FPA, sendo que nos demais meses do ano há o domínio das direções NE a SE. 


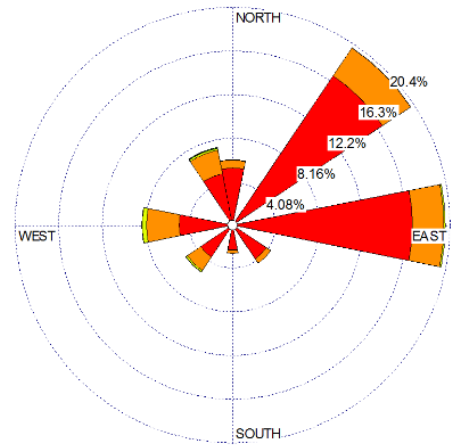

(a)

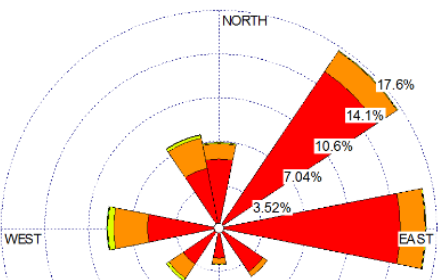

(b)
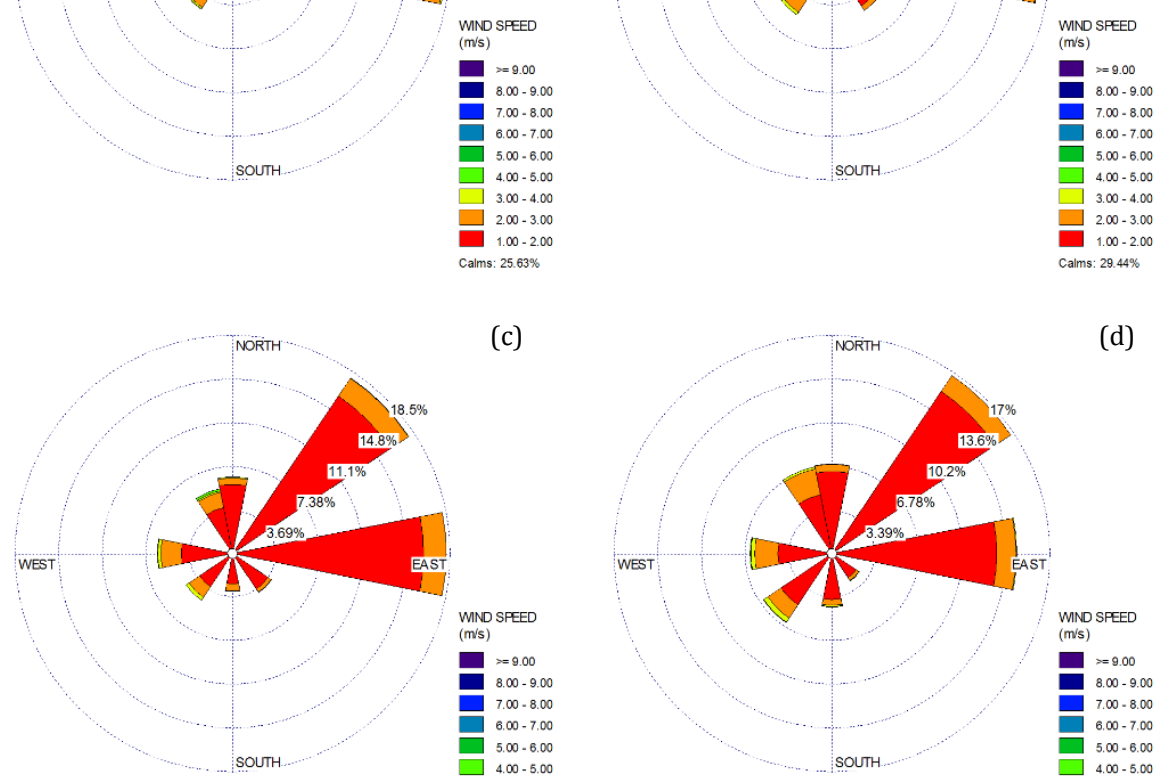

(c)

(d)
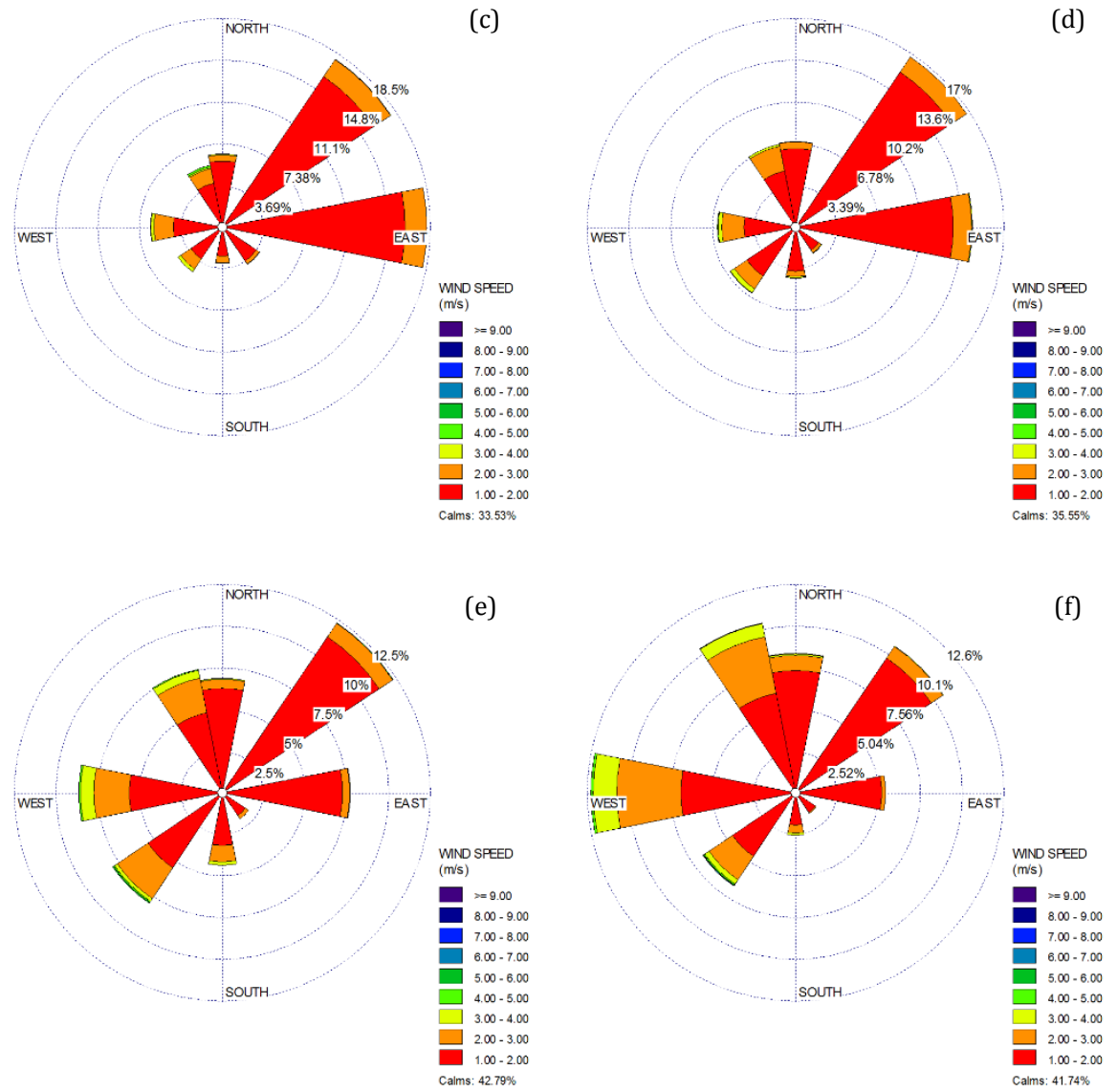

Figura 6 - Rosa dos ventos (\%) para Curitiba nos meses de janeiro (a), fevereiro (b), março (c), abril (d), maio (e) e junho (f). 


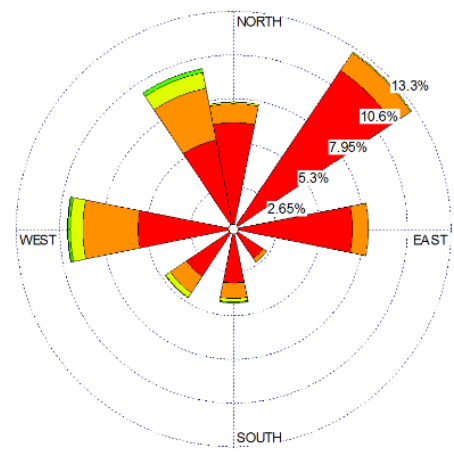

(a)
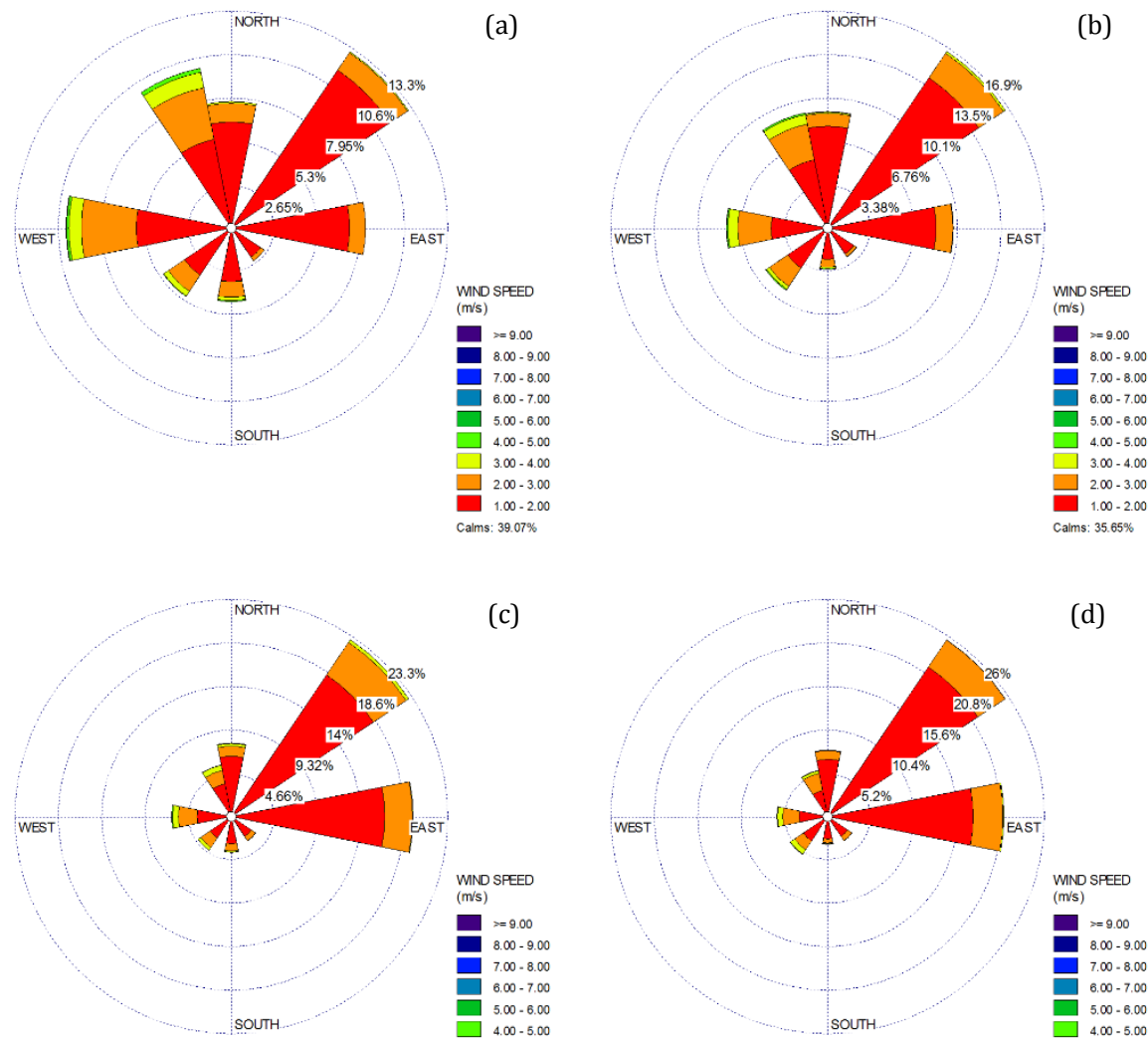

(c)
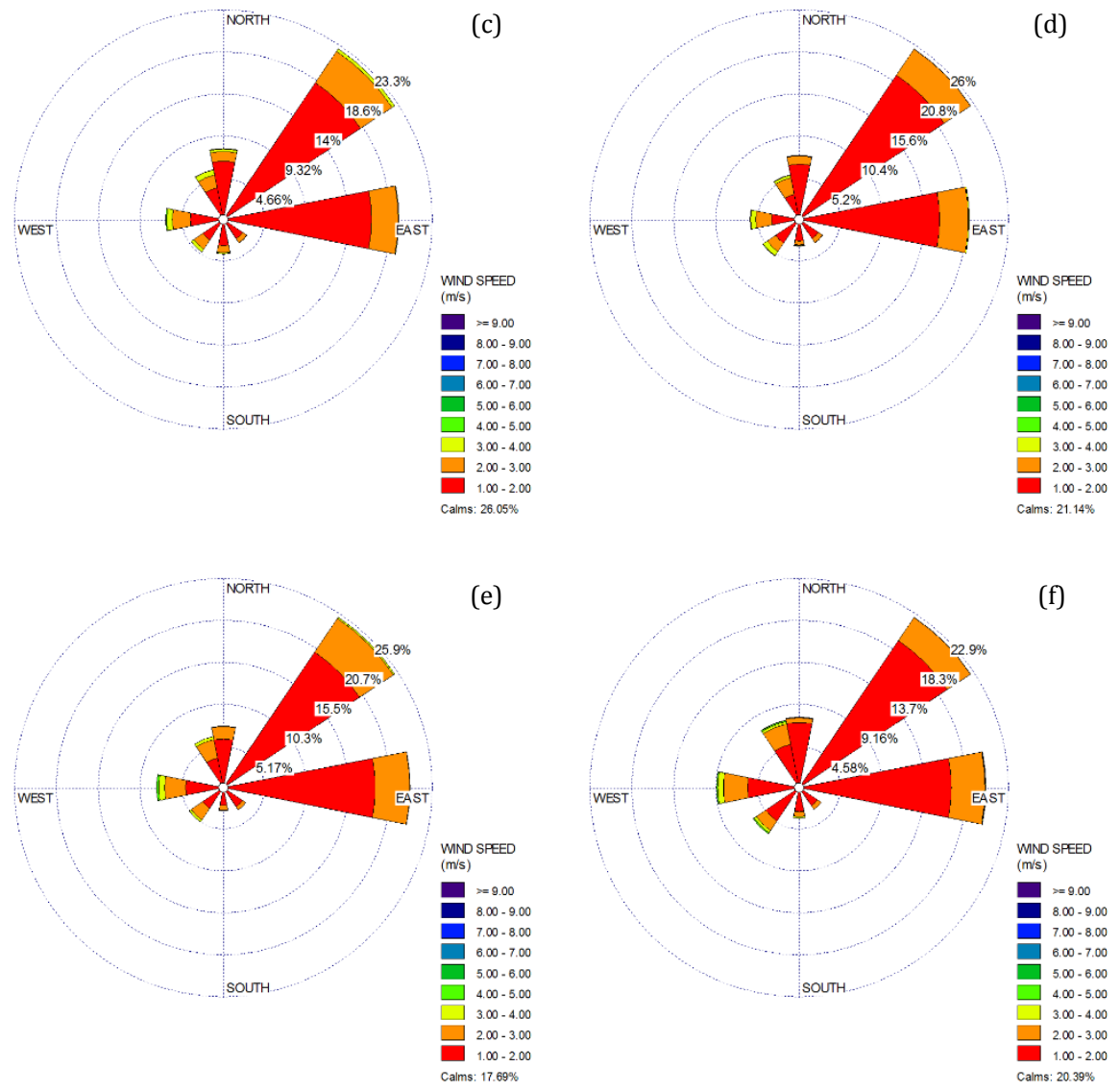

Figura 7 - Rosa dos ventos (\%) para Curitiba nos meses de julho (a), agosto (b), setembro (c), outubro (d), novembro (e) e dezembro (f). 

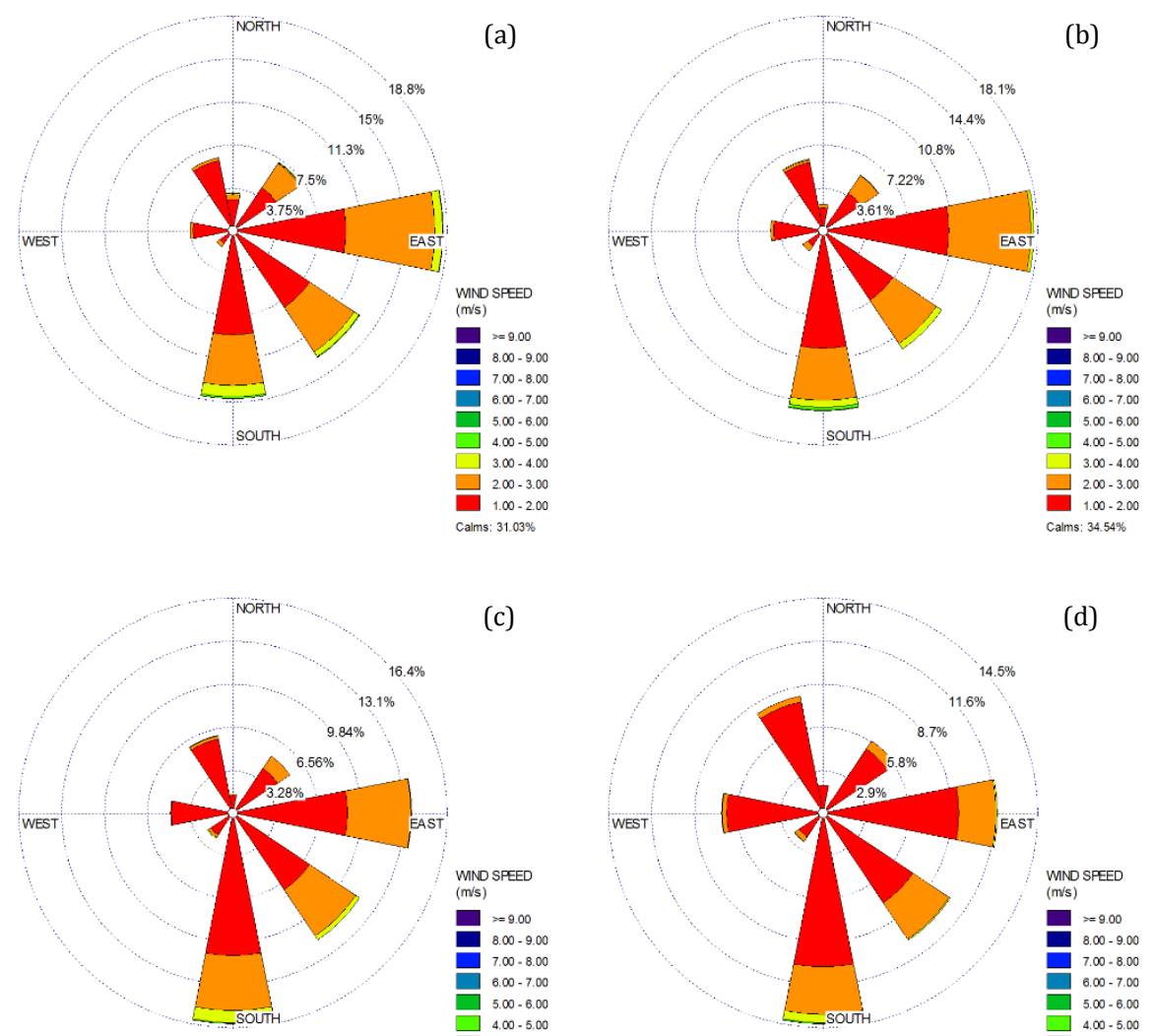

(c)
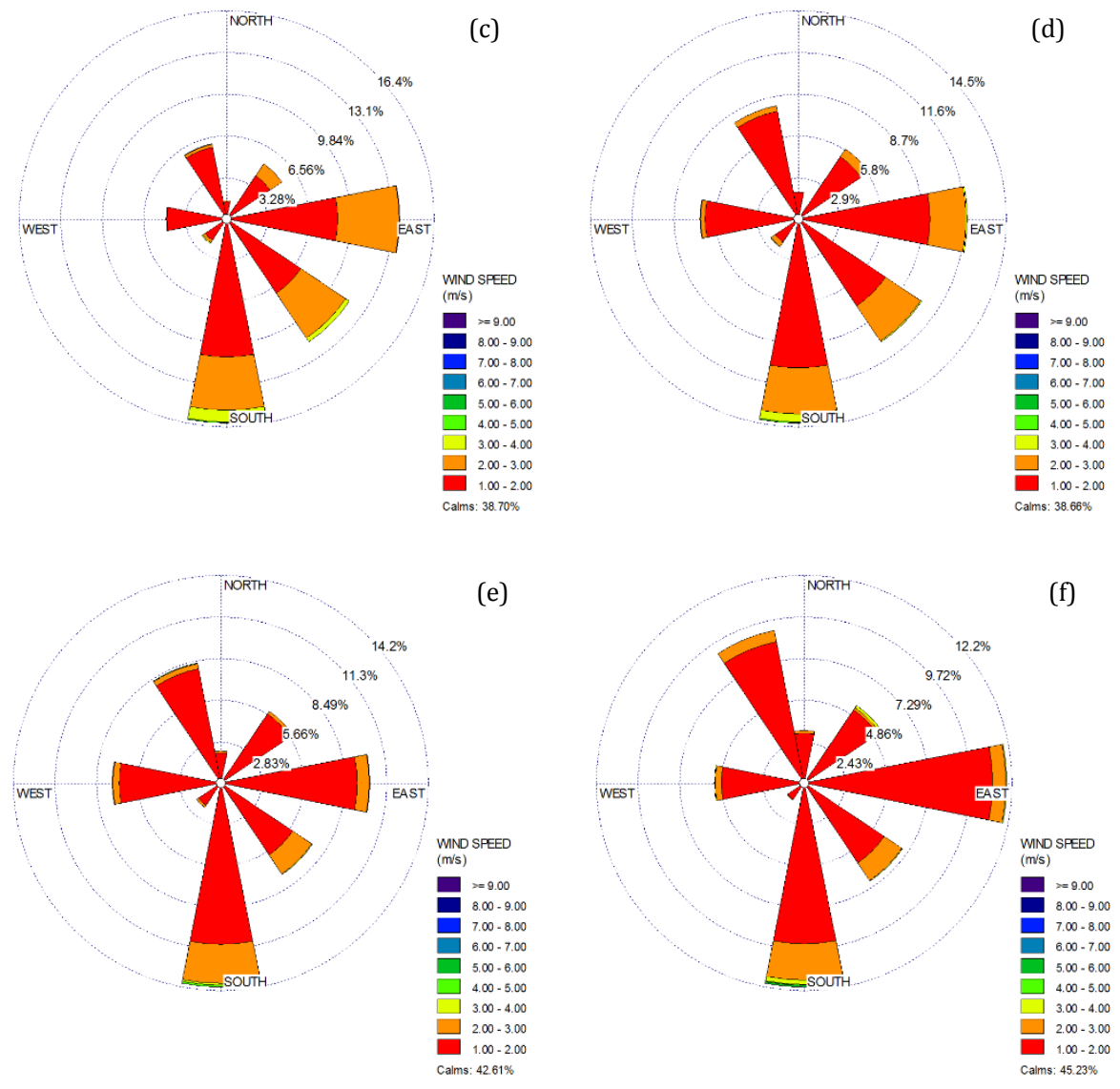

Figura 8 - Rosa dos ventos (\%) para Paranaguá nos meses de janeiro (a), fevereiro (b), março (c), abril (d), maio (e) e junho (f). 

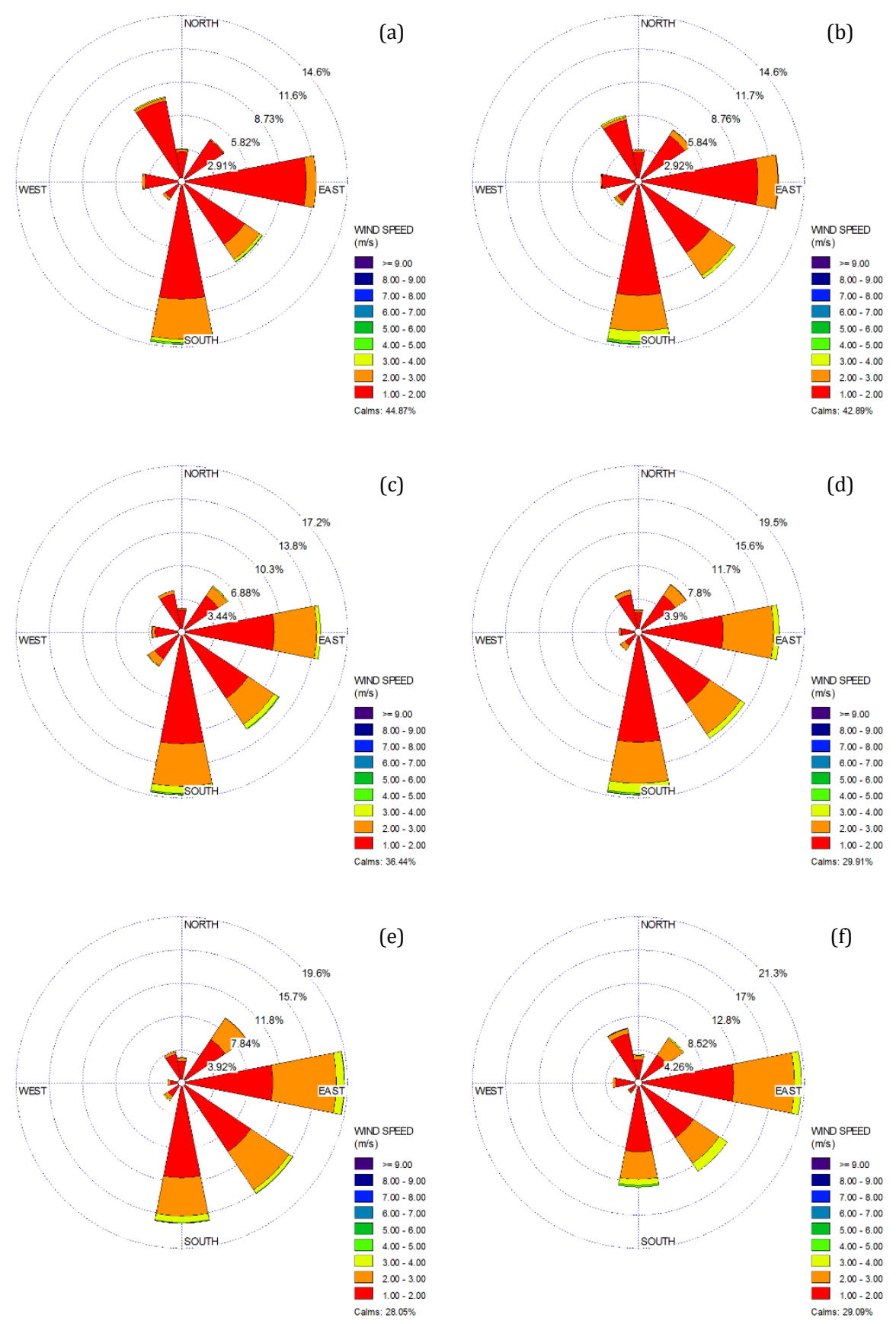

Figura 9 - Rosa dos ventos (\%) para Paranaguá nos meses de julho (a), agosto (b), setembro (c), outubro (d), novembro (e) e dezembro (f).

O período de maiores velocidades dos ventos na área em estudo ocorreu entre os meses de setembro e dezembro, com médias mensais entre 2,37 e 2,61 m. s${ }^{-1}$ em Curitiba e entre 2,24 e 2,56 m. s${ }^{-1}$ em Paranaguá. Observou-se uma situação contrária entre os meses de abril e junho, nos quais se dão as menores velocidades médias mensais, de 1,89 a 2,02 m. s${ }^{-1}$ em Curitiba e de 1,85 a 1,90 m.s-1 para Paranaguá. Visualmente, nota-se que os maiores valores 
mensais do boxplot se dão em Curitiba em relação a Paranaguá, sendo que esta última se caracteriza por uma maior incidência de outliers, condição esperada para uma localidade costeira na qual espera-se a complexidade das condições atmosféricas decorrente das interações entre continente e oceano (Figura 10).

Quanto à direção mensal dos ventos, verifica-se que há em Curitiba uma maior frequência das direções de $135^{\circ}$ e $180^{\circ}$, especialmente entre setembro a maio, com uma maior persistência da direção $135^{\circ}$ de setembro a novembro. 0 aumento dos ventos de direção NW $\left(315^{\circ}\right)$ e W $\left(270^{\circ}\right)$ entre junho e agosto se dão de forma mais efetiva pela maior frequência das passagens dos SF e, deste modo, repercutem no aumento dos valores de direção dos ventos $\left(>180^{\circ}\right)$, com destaque para o mês de junho (Figura 11a). Em Paranaguá, observa-se que há o domínio dos ventos de $\mathrm{S}\left(>180^{\circ}\right)$ entre fevereiro e setembro, sendo que de outubro a janeiro há o predomínio das médias de ventos entre 135 e 180, com o destaque do aumento dos ventos E (Figura 11b).
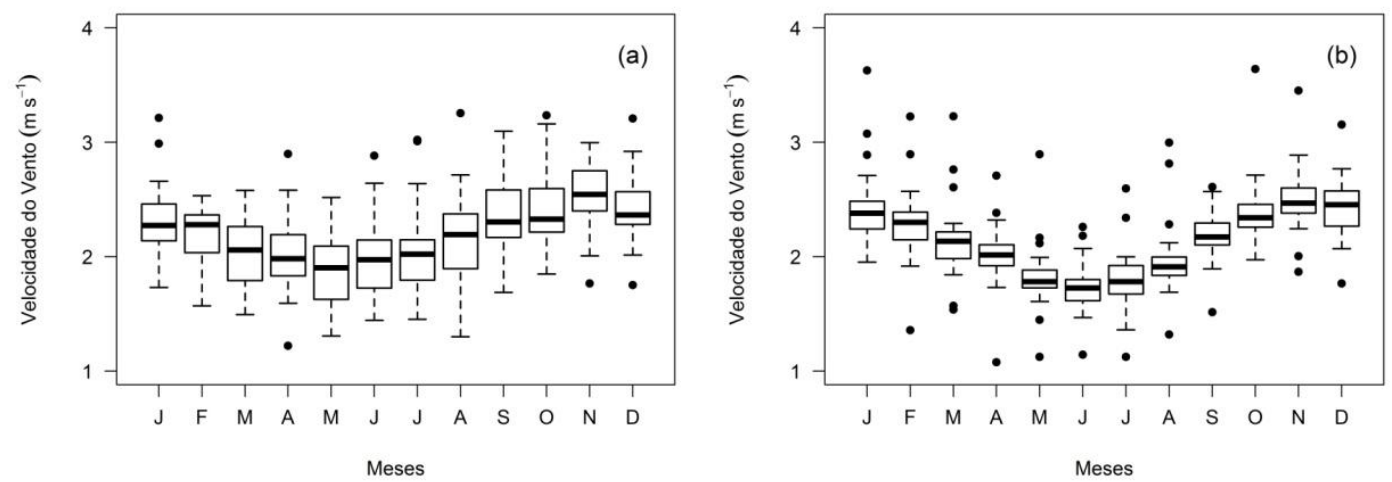

Figura 10 - Boxplot da velocidade média mensal dos ventos $\left(\mathrm{m}^{-1} \mathrm{~s}^{-1}\right)$ em Curitiba (a) e Paranaguá (b), Paraná - Brasil.
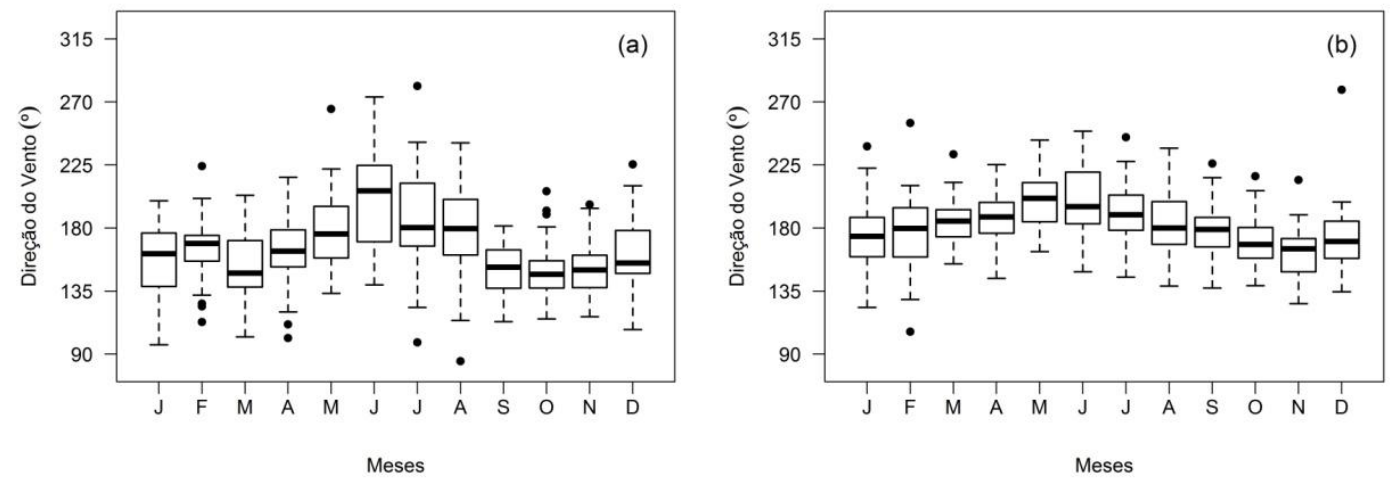

Figura 11 - Boxplot da direção ( $\left.{ }^{\circ}\right)$ média mensal dos ventos em Curitiba (a) e Paranaguá (b), Paraná - Brasil.

\subsection{ESCALA HORÁRIA (09h, 15h, 21h HORAL LOCAL)}

Os resultados para a escala horária mostraram que o período da tarde foi que apresentou maior velocidade média do vento, uma vez que às 15 horas a 
média de calmarias é igual a 14,0\% em Curitiba e a 10,0\% em Paranaguá. A calmaria é equivalente a $38,9 \%$ e a $49,4 \%$ às 9 horas da manhã e a $38,7 \%$ e $51,5 \%$ para as 21 horas em Curitiba e Paranaguá, respectivamente (Figura 12). Em média, a velocidade dos ventos é de 1,90 e $1,48 \mathrm{~m} . \mathrm{s}^{-1}$ às 9 horas e 1,81 m. $\mathrm{s}^{-1}$ e $1,42 \mathrm{~m}$. s $\mathrm{s}^{-1}$ às 21 horas em Curitiba e Paranaguá, concordante com a frequência mais elevada de calmarias nestes horários. Às 15 horas a velocidade

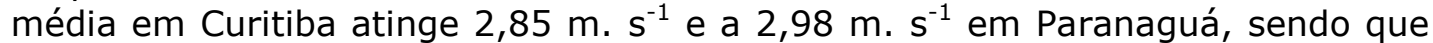
nesta última localidade os ventos atingem uma maior velocidade ao que se atribui ao maior aquecimento (Figura 13).

Os maiores valores da velocidade dos ventos para os outliers se dão às 15 horas e são superiores a $6 \mathrm{~m} . \mathrm{s}^{-1}$ e $7 \mathrm{~m} \cdot \mathrm{s}^{-1}$, ao passo que às 9 horas se dão em $5 \mathrm{~m} . \mathrm{s}^{-1}$ e $3,8 \mathrm{~m} . \mathrm{s}^{-1} \mathrm{~s}^{-1}$ e para as 21 horas em $4,7 \mathrm{~m} \cdot \mathrm{s}^{-1}$ e 3,8 m. s em Curitiba e Paranaguá, nesta ordem. Os valores extremos dos ventos são mais elevados em Curitiba às 9 e 21 horas $\left(8,6 \mathrm{~m} \cdot \mathrm{s}^{-1}\right.$ e $\left.7,4 \mathrm{~m} \cdot \mathrm{s}^{-1}\right)$ em comparação à Paranaguá $\left(5,8 \mathrm{~m} . \mathrm{s}^{-1}\right.$ e $\left.5,7 \mathrm{~m} . \mathrm{s}^{-1}\right)$, enquanto que às 15 horas em Paranaguá o limiar para extremo horário é $10,5 \mathrm{~m} . \mathrm{s}^{-1}$, enquanto que em Curitiba se dá em $8,6 \mathrm{~m}^{-1} \mathrm{~s}^{-1}$ (Figura 13). A ocorrência dos maiores valores dos ventos às 15 horas em Paranaguá ocorre devido ao maior aquecimento superficial e do potencial convectivo e, consequentemente, da maior instabilidade atmosférica, uma vez que esta localidade se caracteriza por uma temperatura média anual $4^{\circ} \mathrm{C}$ em relação à Curitiba (Figura 2) (VANHONI; MENDONÇA, 2008).

Nota-se a predominância dos ventos de diferentes direções nos distintos horários para as duas localidades. Em Curitiba, nota-se o domínio da direção dos ventos de NE e E, variando entre $20,5 \%$ às 9 horas e $41,5 \%$ às 21 horas na soma dos dois quadrantes. Às 9 horas em Paranaguá os ventos sopram em sua maioria de NW $(13,8 \%)$ e S $(12,7 \%)$, enquanto que às 15 horas verifica-se o domínio de ventos de $\mathrm{E}(32,5 \%)$ e SE $(19,8 \%)$ e às 21 horas há o retorno do domínio de ventos de S $(15,5 \%)$ e SE $(9,4 \%)$. Observa-se o aumento da maior velocidade dos ventos às 15 horas, especialmente em Curitiba e oriundos de W e NW (Figura 10).

Castelhano e Roseghini (2018) identificaram resultados semelhantes aos apontados nesta pesquisa para Curitiba. Eles observaram a predominância de ventos de $\mathrm{E}$ e NE em todas as horas do dia, com um aumento gradual a partir das 11 horas de ventos de maiores velocidades, sobretudo superiores a $4 \mathrm{~m} . \mathrm{s}^{-1}$ e do sentido $W$ e NW. Esta condição persiste até às 17 horas, período no qual é verificada a redução da velocidade dos ventos e das direções diferentes de $E$ e NE. Este ciclo diário da velocidade dos ventos é observado com um aumento da velocidade dos ventos em que a mediana da velocidade dos ventos entre as 12 horas e 16 horas é entorno de $2,5 \mathrm{~m} . \mathrm{s}^{-1}$, ligeiramente abaixo dos 2,8 $\mathrm{m} . \mathrm{s}^{-1}$ apontados pela figura 11 para as 15 horas.

Esta alteração dos ventos predominantes no período vespertino é similar ao identificado por Burgardt et al. (2011) para os Campos Gerais, situado no Centro-Leste do Paraná e próximo à Curitiba, pois notaram que nesta região o vento neste horário do dia se dá predominantemente oriundo de NW, sendo que o padrão dos demais horários é de NE ou SE. Especialmente na Lapa, município mais próximo de Curitiba, esta mudança do padrão dos ventos à tarde é mais comum nos meses de fevereiro, março, maio e junho. O aumento da velocidade dos ventos no período vespertino também foi observado para outras localidades 
do Brasil, como por exemplo, observaram Munhoz e Garcia (2008) para Ituverava (SP) e Oliveira-Júnior et al. (2013) para Seropédica (RJ).

Utilizando-se dos dados horários das estações meteorológicas situadas nos aeroportos do Galeão (SBGL) e Santos Dumont (SBRJ), Oliveira-Júnior et al. (2017) identificaram que o aumento significativo da velocidade dos ventos no período das 12 horas às 18 horas está relacionado à mudança da direção dos ventos, similar ao verificado em Curitiba e Paranaguá. No SBRJ, observaram que o efeito da circulação da brisa marítima e terrestre é bastante significativo, pois durante o período da madrugada e manhã os ventos sopravam de $\mathrm{N}$, do continente para o oceano, enquanto que à noite e, principalmente, à tarde os ventos sopravam em um sentido invertido (S) e com maior intensidade. Para o $\mathrm{SBGL}$, mostraram que enquanto de manhã e madrugada os ventos de menores velocidades são oriundos, sobretudo entre os quadrantes de $\mathrm{NW}$ a $\mathrm{E}$, no período da tarde e noite a velocidade aumenta com o domínio de ventos de E a SSE. 

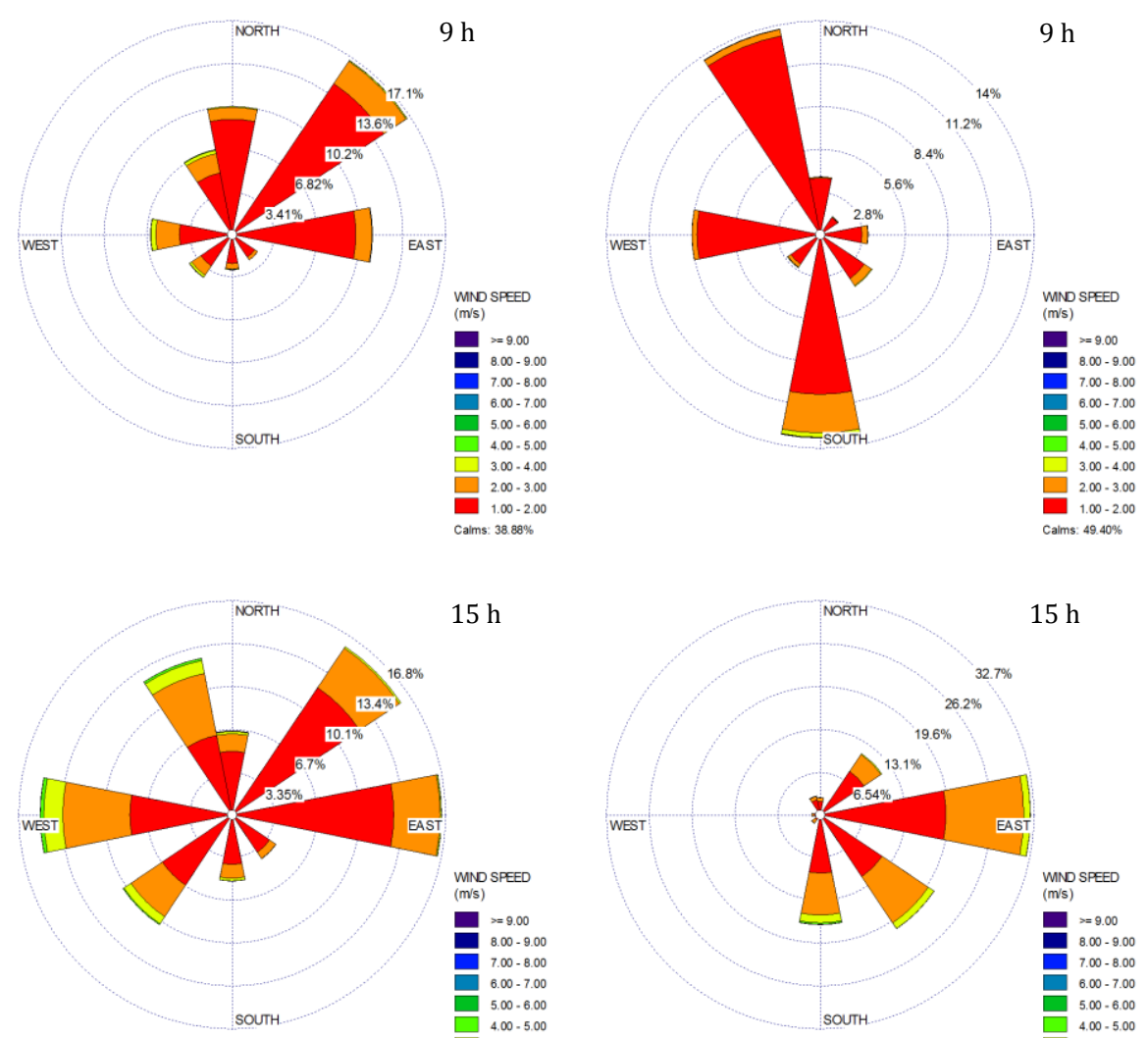

$15 \mathrm{~h}$
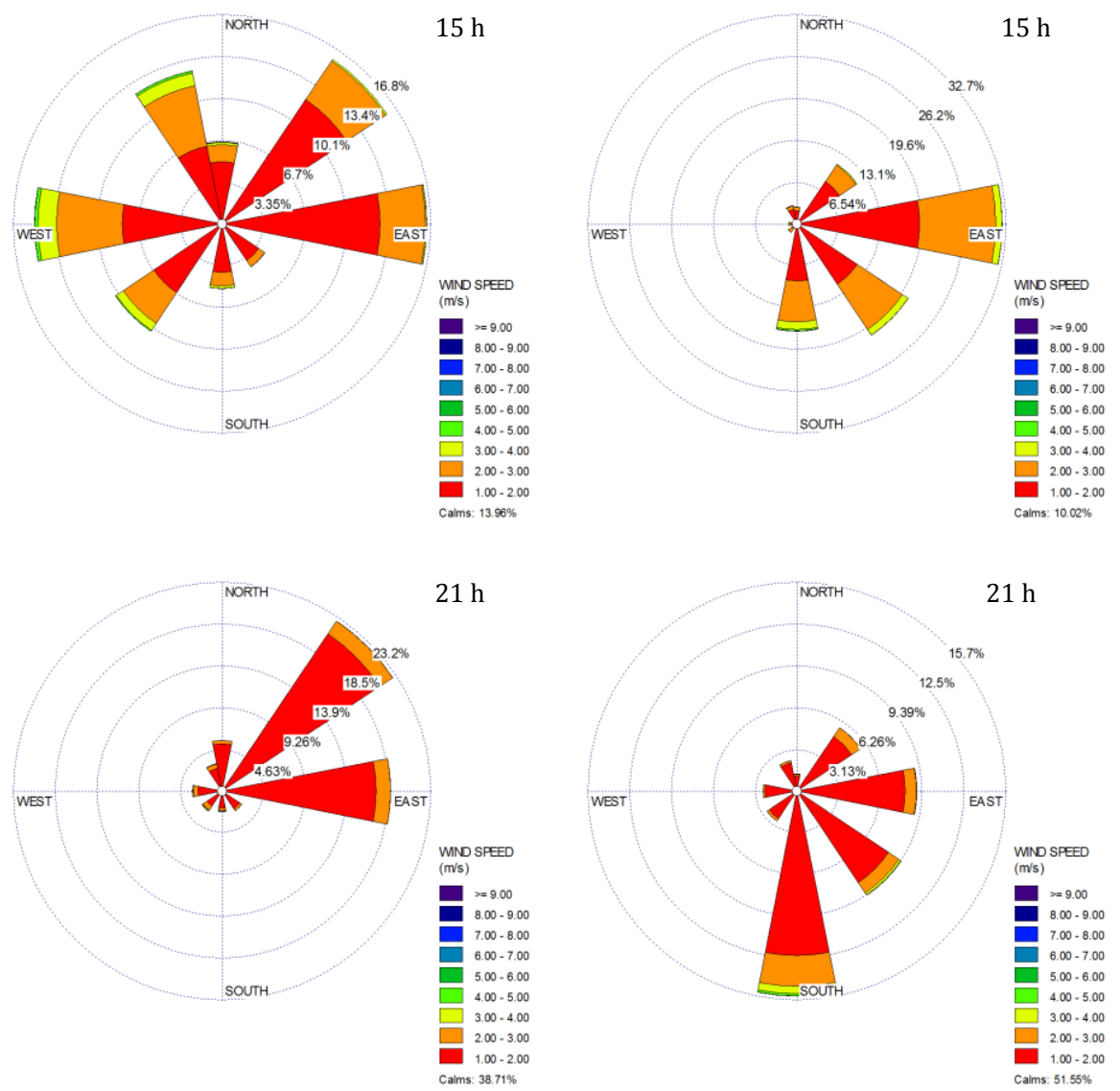

Figura 12 - Rosa dos ventos (\%) para a escala horária em Curitiba (à direita) e em Paranaguá (à esquerda). 

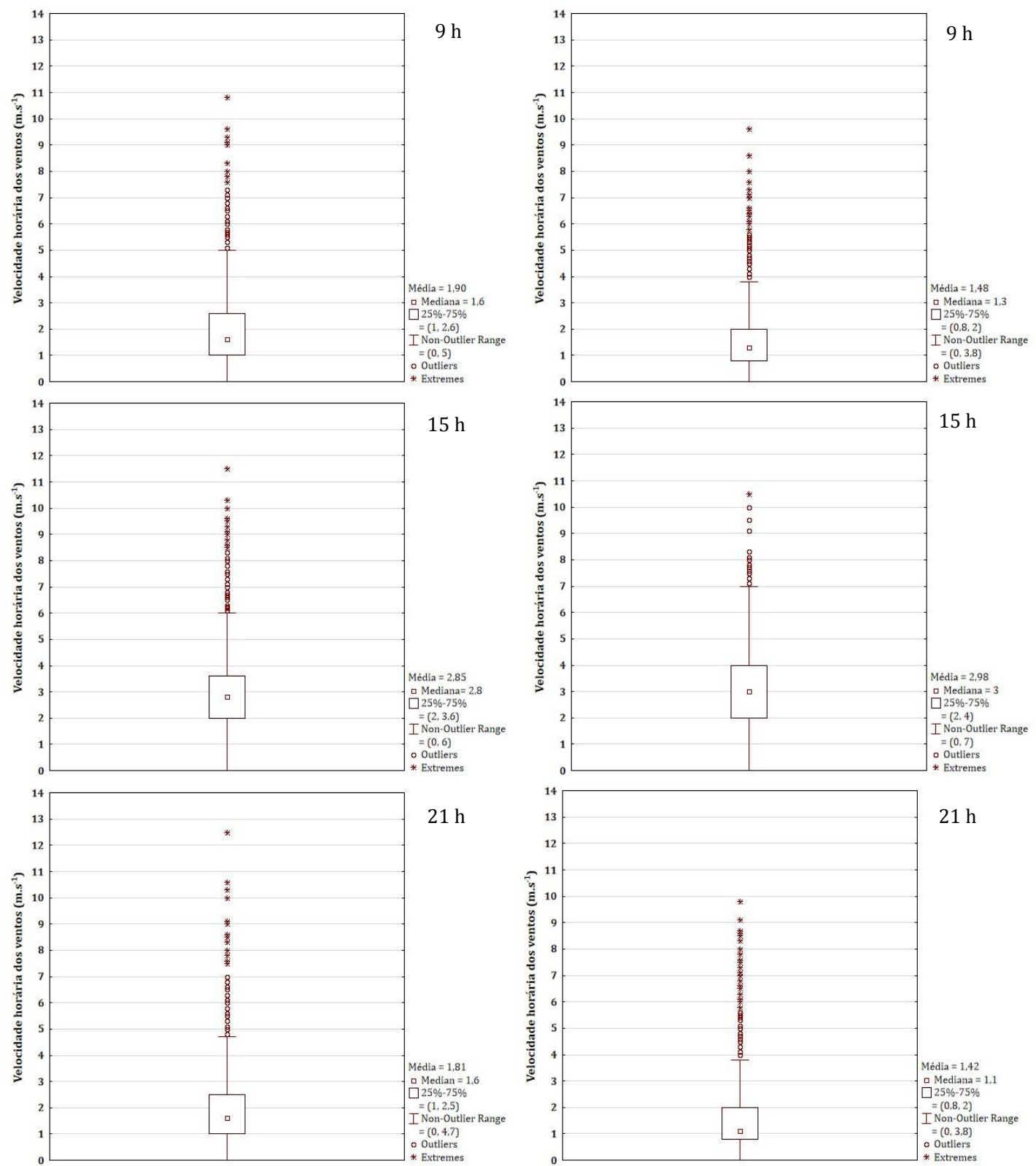

Figura 13 - Boxplot dos ventos para a escala horária em Curitiba (à direita) e em Paranaguá (à esquerda).

\section{CONSIDERAÇÕES FINAIS}

A partir dos resultados obtidos nessa pesquisa, verificou-se que a maior intensidade dos ventos em Curitiba e Paranaguá ocorre entre setembro e outubro, sendo que em novembro ocorrem as maiores médias mensais de velocidade dos ventos e, inversamente, as maiores frequências de calmaria são entre os meses de abril e junho. Em Curitiba há o predomínio dos ventos dos quadrantes de $N E$ a $E$ relacionado à atuação do sistema sinótico (Alta Subtropical do Atlântico Sul). Por sua vez, em Paranaguá a interação entre o relevo da Serra do Mar e o sistema de mesoescala (circulação da brisa 
marítima) condiciona a maior frequência de ventos oriundos de $\mathrm{S}$. O aumento substancial de ventos entre os quadrantes de NW a W em Curitiba (maio a agosto) e Paranaguá (março a julho) estão associadas a maior frequência da incursão da frente polar atlântica.

O ciclo diário apontou o aumento da velocidade dos ventos às 15 horas, atribuída ao aquecimento superficial e à instabilidade atmosférica, sobretudo em Paranaguá, pois esta localidade caracteriza-se por uma temperatura média anual $4^{\circ} \mathrm{C}$ em relação à Curitiba, que às 9 horas e às 21 horas mostrou maiores valores de velocidade dos ventos em relação à Paranaguá. Destaque para o período das 9 horas e das 21 horas a direção dos ventos é em sua maioria é semelhante a verificada para as escalas mensal e anual e, no entanto, às 15 horas há uma mudança das direções predominantes para Paranaguá e em Curitiba, seguido do aumento dos ventos oriundos de W e NW.

\section{AGRADECIMENTOS}

O presente trabalho foi realizado com o apoio financeiro do Programa Nacional de Cooperação Acadêmica da Coordenação de Aperfeiçoamento de Pessoal de Nível Superior - Edital CAPES 071/2013 (88881.068465/2014-01). O primeiro, o quinto e o sétimo autores agradecem à Coordenação de Aperfeiçoamento de Pessoal de Nível Superior (CAPES) pela concessão da bolsa de Doutorado, Pós-Doutorado e Mestrado, nesta ordem. Agradecimentos ao Conselho Nacional de Desenvolvimento Científico e Tecnológico por conceder a Bolsa de Produtividade em Pesquisa - Nível 1D e 2 concedidas ao segundo autor (303676/2013-2) e terceiro autor (306410/2015-0). O quarto autor agradece ao Conselho Nacional de Desenvolvimento Científico e Tecnológico pela concessão da bolsa de Desenvolvimento Tecnológico Industrial - Nível C.

\section{REFERÊNCIAS}

ALVES, E.D.L.; SILVA, S.T. Direção e velocidade do vento em uma floresta de transição Amazônia-Cerrado no norte de Mato Grosso, Brasil. Boletim Goiano de Geografia, Goiânia, v.31, n.1, p.63-74, 2011.

ÁlVARES, C.A.; STAPE, J.L.; SENTELHAS, P.C.; DE MORAES GONÇALVES, J.L.; SPAROVEK, G. Köppen's climate classification map for Brazil. Meteorologische Zeitschrift, Berlin, v.22, n.6, p.711-728, 2013.

APPA (Administração dos Portos de Paranaguá e Antonina). Porto de Paranaguá aumenta em 45\% embarques de grãos. 2018. Disponível em: <http://www.portosdoparana.pr.gov.br/modules/noticias/article.php?storyid=18 05>. Acesso em 27 de fevereiro de 2019.

ARAÚJO JUNIOR, G.N.; QUEIROZ, M.G.; FERRAZ JARDIM, A.M.R.; SILVA, M. J.; PEREIRA, P.C.; SILVA, T.G.F. Caracterização da direção predominante, velocidade máxima e média do vento do município de Petrolina-PE. Pensar Acadêmico, Munhuaçu, v.17, p.43-49, 2019.

BARBANO, M.T.; BRUNINI, O.; PINTO, H.S. Direção predominante do vento para a localidade de Campinas - SP. Revista Brasileira de Agrometeorolo-gia, Santa Maria, v.11, n.1, p.123-128, 2003. 
BERUSKI, G.C.; LEITE, M.L.; VIRGENS FILHO, J.S.; ADACHESKI, P.A.; OLIVEIRA, A.V. Análise probabilística da velocidade média e caracterização da direção do vento predominante no município de Lapa/PR. RA'E GA: o Espaço Geográfico em Análise, Curitiba, v.17, n.1, p.65-75, 2009.

BURGARDT, S.; LEITE, M.L.; VIRGENS FILHO, J.S. Direção horária predominante e de rajada de vento em localidades dos Campos Gerais do Paraná e arredores. Revista Brasileira de Climatologia, Curitiba, v.8, n.1, p.137-151, 2011.

CARDOSO, C.S.; BITENCOURT, D.P.; MENDONCA, M. Comportamento do vento no setor leste de Santa Catarina sob influência de ciclones extratropicais. Revista Brasileira de Meteorologia, São Paulo, v.27, n.1, p.39-48, 2012.

COSTA, G.B.; LYRA, R.F.F. Análise dos padrões de vento no estado de Alagoas. Revista Brasileira de Meteorologia, São Paulo, v.27, n.1, p31-38, 2012.

CARNEIRO, T.C.; CARVALHO, P.C.M. Caracterização de potencial eólico: estudo de caso para Maracanaú (CE), Petrolina (PE) e Parnaíba (PI). Revista Brasileira de Energia Solar, Recife, v.6, n.1, p.1-10, 2015.

CASTELHANO, F.J.; ROSEGHINI, W.F.F. Caracterização da dinâmica dos ventos em Curitiba-PR. Geousp: Espaço e Tempo, São Paulo, v.22, n.1, p.227-240, 2018.

DALLACORT, R.; MOREIRA, P.S.P.; INOUE, M.H.; SILVA, D.J.; CARVALHO, I.F.; SANTOS, C. Wind speed and direction characterization in Tangará da Serra, Mato Grosso State, Brazil. Revista Brasileira de Meteorologia, São Paulo, v.25, n.3, p.359-364, 2010.

DANNI-OLIVEIRA, I.M. Considerações sobre a poluição do ar em Curitiba - PR face a seus aspectos de urbanização. RA'E GA: o Espaço Geográfico em Análise, Curitiba, v.4, n.1, p.101-110, 2000.

DUBREUIL, V.; FANTE, K.P.; PLACHON, O.; SANT'ANNA NETO, J.L. Les types de climats annuels au Brésil: une application de la classification de Köppen de 1961 à 2015. EchoGéo, Paris, v.3, n.41, p.1-27, 2017.

GALVANI, E.; KLOSOWSKI, E.S.; CUNHA, A.R.; MARTINS, D. Caracterização da direção predominante do vento em Maringá-PR. Revista Brasileira de Agrometeorologia, Santa Maria, v.7, n.1, p.81-90, 1999.

IBGE (Instituto Brasileiro de Geografia e Estatística). Conheça cidades e estados do Brasil. 2018. Disponível em: <https://cidades.ibge.gov.br/>. Acesso em 27 de fevereiro de 2019.

INMET (Instituto Nacional de Meteorologia). Gráficos Climatológicos. 2018. Disponível em: <http://www.inmet.gov.br/portal/index.php?r=clima/graficosCli

maticos>. Acesso em 28 de fevereiro de 2018.

INMET (Instituto Nacional de Meteorologia). BDMEP (Banco de Dados Meteorológicos para Ensino e Pesquisa). 2019. Disponível em: < http://ww

w.inmet.gov.br/portal/index.php?r=bdmep/bdmep $>$. Acesso em 28 de fevereiro de 2018.

LAKES (Lakes environmental software). Wind Rose Plots For Meteorological Data

- WRPLOT View. 2017. Disponível em: <http://www.weblakes.com/prod 
uts/wrplot/index.html. >. Acesso em 20 de março 2018.

LEITE, M.L.; VIRGENS FILHO, J.S. Avaliação da velocidade média e direção predominante do vento em Ponta Grossa - PR. Revista Brasileira de Agrometeorologia, v.14, n.2, p.157-167, 2006.

MAACK, R. Geografia Física do Estado do Paraná. 4a Edição. Ponta Grossa: Editora UEPG. 2012. 526p.

MALEKI, H.; SOROOSHIAN, A.; GOUDARZI, G.; NIKFAL, A.; BANESHI, M. M. Temporal profile of PM10 and associated health effects in one of the most polluted cities of the world (Ahvaz, Iran) between 2009 and 2014. Aeolian research, v. 22, p. 135-140, 2016.

MELLO, Y.R.; LOPES, F.C.A.; ROSEGHINI, W.F.F. Características climáticas e análise rítmica aplicada a episódios extremos de precipitação e temperatura no município de Paranaguá, PR. Revista Brasileira de Climatologia, Curitiba, v.20, n.1, p.313-336, 2017.

MUNHOZ, F.C.; GARCIA, A. Caracterização da velocidade e direção predominante dos ventos para a localidade de Ituverava-SP. Revista Brasileira de Meteorologia, São Paulo, v.23, n.1, p. 30-34, 2008.

OLIVEIRA, D.; BORROZZINO, E. Tendências de alteração da velocidade do vento no estado do Paraná. Agrometeoros, Passo Fundo, v.26, n.1, p.145-149, 2018.

OLIVEIRA JÚNIOR, J.F.; SOUZA, J.C.S.; DIAS, F.O.; GOIS, G.; GONÇALVES, I.F.S.; SILVA, M.S. Caracterização do regime de vento no município de Seropédica, Rio de Janeiro (2001-2010). Floresta e Ambiente, Seropédica, v.20, n.4, p.447-459, 2013.

OLIVEIRA JÚNIOR, J.F.; PIMENTEL, L.C.G.; LANDAU, L. Critérios de Estabilidade Atmosférica para a Região da Central Nuclear Almirante Álvaro Alberto, Angra dos Reis-RJ. Revista Brasileira de Meteorologia, São Paulo, v. 25, n. 2, p. $270-$ 285, 2010.

OLIVEIRA JÚNIOR, J.F.; TERASSI, P.M.B.; GOIS, G. Estudo da circulação dos ventos na Baía de Guanabara/RJ, entre 2003 e 2013. Revista Brasileira de Climatologia, Curitiba, v.21, n.2, p. 59-80, 2017.

PIMENTEL, L.C.G.; MARTON, E.; SILVA, M.S., JOURDAN, P. Caracterização do regime de vento em superfície na Região Metropolitana do Rio de Janeiro. Revista de Engenharia Sanitária e Ambiental, Rio de Janeiro, v.19, n.2, p.121132, 2014.

R CORE TEAM. 2016. R: A language and environment for statistical computing. $\mathrm{R}$ Foundation for Statistical Computing, Vienna, Austria. Disponível em: https://www.R-project.org/. Acesso em 14 de maio de 2017.

RANGEL, R.H.O.; OLIVEIRA-JÚNIOR, J. F.; TORRES JÚNIOR, A. R.; PIMENTEL, L.C.G.; GOIS, G. Série e Transformada de Fourier Aplicadas no Preenchimento de Falhas de Séries Temporais de Intensidade do Vento na Central Nuclear Almirante Álvaro Alberto, Rio de Janeiro - Brasil. Anuário do Instituto de Geociências - UFRJ, Rio de Janeiro, v. 41, p. 74-84, 2018.

REBOITA, M.S.; GAN, M.A.; ROCHA, R.P.; AMBRIZZI, T. Regimes de precipitação na América do Sul. Revista Brasileira de Meteorologia, São Paulo, v.25, n.2, p.185-204, 2010. 
REBOITA, M.S.; ASSIREU, A.; SILVA, L.C.; RIOS, N. Evidências de Circulação de Brisa Vale-Montanha na Serra da Mantiqueira: Cidade de Itajubá - MG. Ciência \& Natura, Santa Maria, v.36, n.1, p.61-71, 2014.

REBOITA, M.S.; KRUCHE, N. Normais climatológicas provisórias de 1991 a 2010 para Rio Grande (RS). Revista Brasileira de Meteorologia, São Paulo, v.33, n.1, 2018.

SILVA, J. B.; ZANUSSO, J. T.; SILVEIRA, D. L. M.; SCHONS, R. L.; LARROZA, E. G. Estudo da direção e velocidade dos ventos em Pelotas, RS. Revista Brasileira de Agrometeorologia, Santa Maria, v.5, n.2, p.227-235, 1997.

SILVA, C.; PIMENTEL, L.C.G.; LANDAU, L.; HEILBRON FILHO, P.F.L.; GOBBO, F.G.R.; SOUSA, P.J. Supportive elements to the decision-making process in the emergency planning of the Angra dos Reis Nuclear Power Complex,Brazil. Environmental Earth Sciences, Melbourne, v.76, n.133, p.1-16, 2017.

SILVA, B.B.; ALVES, J.J.A; AZEVEDO, F.G.B.; CAVALCANTI, E.P.; DANTAS, R., T. Potencial eólico na direção predominante do vento no Nordeste brasileiro. Revista Brasileira de Engenharia Agrícola e Ambiental, Campina Grande, v.6, n.3, 2002.

SILVA, B.B.; ALVES, J.J.A.; CAVALCANTI, E.P.; VENTURA, E.D. Variabilidade espacial e temporal do potencial eólico da direção predominante do vento no nordeste do Brasil. Revista Brasileira de Meteorologia, São Paulo, v.19, n.2, p.189-202, 2004.

SILVA, D.G.; LOPES, R.P.; CARVALHO, D.F. Caracterização do potencial eólico em Seropédica (RJ). Engenharia Agrícola, Botucatu, v.28, n.3, p.185-192, 2013.

SILVA, R. L.; VIEIRA, M. M. Direção predominante, velocidade do vento e suas frequências de ocorrência em Dourados-MS. Energia na Agricultura, Botuca-tu, v.31, n.4, p.348-355, 2016.

SOBRAL, B.S.; OLIVEIRA JUNIOR, J.F.; TERASSI, P.M.B.; GOIS, G. Regime de Vento na Serra do Mar - Rio de Janeiro, Brasil. Revista Brasileira de Meteorologia, São Paulo, v.33, n.3, p.441-451, 2018.

SOUSA, J.W. Análise climatológica do potencial eólico no Estado de Minas Gerais. 1993. 107f. Dissertação (Mestrado). Programa de Pós-Graduação em Agronomia, Universidade Federal de Viçosa, Viçosa, 1993.

TERASSI, P.M.B.; GALVANI, E. Identification of homogeneous rainfall regions in the eastern watersheds of the State of Paraná, Brazil. Climate, Basel, v.5, n.3, p.53-65, 2017.

TERASSI, P.M.B.; GALVANI, E. Análise da frequência e da intensidade das precipitações extremas diárias em Curitiba e Paranaguá - Paraná, Brasil. In: GALVANI, E.; GOBO, J.P.A.; LIMA, N.G.B. Climatologia Aplicada II.1 ${ }^{a}$ Edição, CRV: Curitiba, p.180-191, 2018.

TRUCCOLO, E.C. Assessment of the wind behavior in the northern coast of Santa Catarina. Revista Brasileira de Meteorologia, v.26, n.3, p.451-460, 2011.

VANHONI, F.; MENDONCA, F. A. O clima no litoral do Estado do Paraná. Revista Brasileira de Climatologia, Curitiba, v.3, n.1, p.49-64, 2008. 
VENEZIANI, Y.; GALVANI, E.; RANZINI, M. Características de ventilação do núcleo Cunha, Parque Estadual da Serra do Mar, SP. Revista Brasileira de Climatologia, Curitiba, v.12, n.1, p.155-171, 2013.

WAHRLICH, J.; SILVA, F.A.; CAMPOS, C.G.C.; RODRIGUES, M.L.G.; MEDEIROS, J. Characterization of the predominant wind speed and direction in Santa Catarina, Brazil. Revista Brasileira de Climatologia, Curitiba, v.23, n.1, p.356-373, 2018.

ZANDONADI, L.; ACQUAOTTA, F.; FRATIANNI, S.; ZAVATTINI, J. A. Changes in precipitation extremes in Brazil (Paraná River Basin). Theoretical and Applied Climatology, Berlim, v.119, n.1, p.1-18, 2015.

ZERI M.; OLIVEIRA-JÚNIOR, J.F.; LYRA, G.B. Spatiotemporal analysis of particulate matter, sulfur dioxide and carbon monoxide concentrations over the city of Rio de Janeiro, Brazil. Meteorology and Atmospheric Physics (Print), Berlim, v.113, n.3, p.1-14, 2011. 